\title{
1 Testate amoebae as a hydrological proxy for reconstructing 2 water-table depth in the mires of south-eastern Australia
}

\author{
3 Xianglin Zheng ${ }^{1}$, Matthew J. Amesbury ${ }^{2}$, Geoffrey Hope ${ }^{3}$, Len F. Martin ${ }^{1}$ and Scott D. Mooney ${ }^{1 *}$
}

4

$5 \quad{ }^{1}$ School of Biological, Earth \& Environmental Sciences, University of New South Wales, Australia

$6{ }^{2}$ Geography, College of Life and Environmental Sciences, University of Exeter, UK

$7 \quad{ }^{3}$ Department of Archaeology and Natural History, Australian National University, Australia

$8 \quad$ *Corresponding author: s.mooney@unsw.edu.au

\section{Abstract:}

Although it is well established that moisture availability in south-eastern Australia has been decreasing through time recently, the driver(s) of this trend are contentious, and our understanding of any drivers is limited by a relatively short historic record. Testate amoebae have been widely used to reconstruct peatland hydrology in the Northern Hemisphere, but in the Southern Hemisphere research is still needed to assess their proficiency as a palaeohydrological proxy and to develop robust transfer functions. Here we examine the ecology of testate amoebae in several high altitude mires in south-eastern Australia and present the first transfer function for the continent. Euglypha tuberculata type, Centropyxis platystoma type and Assulina muscorum were the most common taxa in our modern samples. Water-table depth was the primary environmental variable determining testate amoebae assemblages and therefore transfer functions were developed for this ecological factor. We found that the performance of various all-species and species-pruned transfer functions were statistically robust, with $R^{2}$ values of around 0.8 and Root Mean Squared Error of Prediction (RMSEP) values of about $7 \mathrm{~cm}$. All cross-validation methods (leave-one-out RMSEP, cluster-bootstrap RMSEP, segment-wise RMSEP and leave-one-site-out RMSEP from all-species and species-pruned transfer functions) suggested that the Modern Analogue Technique (MAT) was the best performing transfer function, with negligible bias evident from un-even sampling and spatial autocorrelation. We also used a new approach to evaluate the importance of taxa and the performance of our transfer functions using species-pruned methods. Our results suggest that the all-species MAT, with an RMSEP of 5.73 and $\mathrm{R}^{2}$ of 0.86 , provides the best reconstruction of water-table depth across our sites in south-eastern Australia.

Keywords: testate amoebae; Australia; transfer function, species-pruned, water-table depth, 


\section{Introduction}

The instrumental record of rainfall in south-eastern Australia is relatively short ( 110 years) but shows a number of significant droughts including the Millennium Drought (1996-2010), the World War II Drought (1937-1945) and the earlier Federation Drought (1895-1902) (Timbal and Fawcett, 2013). A long-term decline in rainfall in south-eastern Australia is also apparent across the last 60 years (Australian Bureau of Meteorology, 2016) and this has been especially true for autumn or winter rainfall (Delworth and Zeng, 2014). It has been suggested that this trend, or the length and/or severity of these droughts, might represent or be exaggerated by anthropogenic climate change (Delworth and Zeng, 2014; Timbal and Fawcett, 2013).

Verdon-Kidd and Kiem (2009) demonstrated that different large-scale drivers influenced the spatial extent of these droughts across the Australian continent, however the relatively short instrumental record limits a complete understanding of this variability (CSIRO, 2010). A better understanding of the frequency, trends and drivers of rainfall obviously requires longer records than are available using instrumental data. This has recently been addressed using a network of drought-sensitive treering chronologies (and one coral record), resulting in the Australian and New Zealand summer drought atlas (Palmer et al., 2015), however this also only extends to AD 1500.

Several other proxies sensitive to moisture are available in south-eastern Australia, including peat humification, pollen, speleothems and lake, river and dune geomorphology (Kemp and Spooner, 2007; Wilkins et al., 2013; McGowan et al., 2009; Gergis et al., 2012; Jones et al., 2001; Black et al., 2008; Ayliffe et al., 1998; Kemp and Rhodes, 2010). However, while longer, these records often only provide qualitative observations of moisture availability. Lake level reconstructions (Wilkins et al., 2013; Bowler and Hamada, 1971; Harrison, 1993) are perhaps the most widely used palaeoenvironmental proxies of moisture availability in the region but their temporal resolution are often too coarse to identify individual drought events. Transfer functions between pollen and rainfall have been tested in south-eastern Australia (Cook and van der Kaars, 2006) but have not generated any further reconstruction.

Testate amoebae, one of only a few moisture sensitive proxies, have been used extensively in the Northern Hemisphere for quantifying peatland water-table depth (WTD) (Mitchell et al., 2008; Amesbury et al., 2016). WTD is thought to be a reliable moisture index, and in comparison with moisture content, is less susceptible to short-term variability (Charman et al., 2007). Research comparing instrumental hydrological records and reconstructed WTD based on testate amoebae by Swindles et al. (2015) demonstrated that the relationships have sufficient strength to allow consideration of change in moisture status.

There has been limited research on testate amoebae in Australia, with only two publications on their modern ecology (Meisterfeld and Tan, 1998; Bamforth, 2015). In New Zealand research is also relatively sparse (McGlone and Wilmshurst, 1999; Hazell, 2004; Charman, 1997; Bamforth, 2015), although a WTD reconstruction has been published, despite issues with preservation (Wilmshurst et al., 2003).

Notably, most testate amoebae research in the Northern Hemisphere has been conducted in ombrotrophic peatlands (Payne and Mitchell, 2007), where WTD reflects a balance between rainfall 
and evaporation. Ombrotrophic mires are exceedingly rare in south-eastern Australia (Whinam et al., 2003), as most organic deposits in the region are minerotrophic, topogenous fens such that they receive water and other allochthonous materials from within the catchment. This characteristic means that standard testate amoebae laboratory protocols (Barnett et al., 2013; Charman et al., 2010; Booth et al., 2010) result in difficult preparations and low total counts, which are potentially inappropriate for statistical analysis. These problems are common in the analysis of testate amoebae in minerotrophic peatlands (fens), salt marshes and other near-coastal sediments (Charman et al., 2010; Swindles et al., 2016; Payne, 2011). Furthermore, regional variations in testate amoebae community composition mean that any derived transfer function is most applicable to the spatial extent of the modern calibration set. Some taxa are exclusive to the Southern Hemisphere while certain taxa are Gondwanic, such as Certesella certesi and Apodera vas (van Bellen et al., 2014; Smith et al., 2008) therefore it is necessary to build a south-eastern Australian regional transfer function for further reconstruction.

Juggins (2013) noted that any palaeo-environmental reconstruction requires preliminary research to demonstrate that the variable of interest is ecologically important, however this is sometimes overlooked. In order to test if testate amoebae can be used as a quantitative proxy for moisture availability in south-eastern Australia, this research aimed to: (1) explore the ecology of testate amoebae in south-eastern Australia; (2) determine if a significant relationship exists between testate amoebae community composition and WTD; and, (3) generate a transfer function between testate amoebae and WTD for south-eastern Australia. The research is hence fundamental to the future use of any transfer function between testate amoebae and WTD in south-eastern Australia.

\section{Field and Laboratory Methods:}

We first sampled a wide distribution of mires in south-eastern Australia but quickly discovered that standard protocols for the concentration of testate amoebae from minerotrophic sediments left siltsized detrital material, which obscured the tests on the slides and made counting extremely difficult. We then focused our sampling in relatively high altitude mires in southern New South Wales (NSW) and the Australia Capital Territory (ACT) (Fig. 1; Table 1). The ACT sites (Blundells Flat, Snowy Flat, Coronet Creek and Tom Gregory Bog) were sampled in October 2015 and Ginini Flat and the NSW mires in Kosciuszko National Park (Rennix Gap, Digger Creek and Pengillys Bog) were sampled in April 2016.

Mires in south-eastern Australia are characterised by low free surface water and low nutrient status (Hope et al., 2012). Almost all the sites we sampled are topogeneous mires, occupying the base of slopes and valley floors and they receive water via slope runoff and groundwater flows. Nonetheless we chose locations for sampling within the mires with more ombrotrophic characteristics. All sampled sites include patches of Sphagnum-dominated vegetation, with the exception of Blundells Flat which is better characterised as a relatively low altitude Carex (Cyperaceae) fen, nonetheless they are often dominated by Empodisma (Restionaceae), Epacris (Ericacaeae), Richea (Ericaceae) or Carex (Cyperaceae) (Table1). 
To minimize the effect of clumped data and uneven sampling (Telford and Birks, 2011; Payne et al., 2012), it is better to sample evenly at individual sites and across environmental gradients of interest. Therefore between 9 and 12 samples were taken at each site, with the exception of Coronet Creek, where we took 1 sample, as the site is small and homogenous with a constant WTD. At all other sites we took samples in 3 or 4 transects which covered the range of WTD, often from the top of the hummocks to the lawn or the pool of the hollow. In all cases the peat or moss surface was taken as zero depth, with negative WTD values representing a subsurface water-table and positive values standing water. Our modern sediment samples were collected from 5-10 cm depth. 'Modern' samples from Sphagnum-dominated sites are usually taken from below the uppermost living moss as the community composition is more likely to be consistent with the sub-fossil testate amoeba (Woodland et al., 1998; Booth et al., 2010). For the more minerogenic sites or samples we also sampled from $5-10 \mathrm{~cm}$ but recognise that these samples may be older, depending on the sedimentation rate, and that the testate amoeba community potentially represents altered WTD. When we sampled from within pools, the top $5 \mathrm{~cm}$ of the sediment was kept. We measured WTD once, which is considered representative of relative moisture availability (Holden et al., 2011; Woodland, 1996; Amesbury et al., 2013), after the water level stabilised in an open pit or as standing water in the pools. We also took water samples from this pit or from the pools for laboratory analysis of $\mathrm{pH}$ and electrical conductivity (EC). Moisture content was measured as mass lost after 24 hours in a $105^{\circ} \mathrm{C}$ fan forced oven.

The majority of our modern samples had a high organic content and, as mentioned, standard protocols for the concentration of testate amoebae resulted in slides dense with organic and inorganic particles, which potentially obscured taxa. A revised methodology, adapted from the mildalkali method of Charman et al. (2010) incorporating detergent and acetone, was developed to mitigate this issue (Supplementary Table 1) and to minimise damage to the testate amoebae. We used detergent to aid in the dispersal of organic matter, as is sometimes used for palynology (Faegri and Iversen, 1964) and we added acetone to our protocol to increase the interaction between the mild alkali treatment $(\mathrm{NaOH})$ and the organic matter. The addition of acetone increases the removal of humic acids and the solubility of organic matter (Jason Harper pers. comm.). We used three nested sieves $(250,215$ and $20 \mu \mathrm{m})$, with the top sieve used as a cushion to reduce the strength of the flushing water. The material retained between the 215 and $20 \mu \mathrm{m}$ sieves was used for the quantification of the testate amoebae.

A minimum of 100 individual tests was counted in each sample (with the exception of sample TGB1, where only 98 individuals were quantified) as this has been suggested as sufficient for transfer function development (Payne and Mitchell, 2009; Charman et al., 2010) and each taxon was converted into a percentage of the total count. Two samples (BF3 and BF7) were excluded from the dataset as they had an extremely low concentration of testate amoebae. Identification of the testate amoebae followed Sullivan and Booth (2007) which was based on Charman et al. (2000). Southern Hemisphere endemic taxa were identified using Patagonian references (van Bellen et al., 2014) 
those found in Patagonia. We also recorded Nebela vitraea type as Argynnia dentistoma type, and Nebela griseola type as Physochila griseola type (Amesbury et al., 2016). One undescribed taxon was identified in our samples and included in the database as 'Nebela sp1' (for a picture and details see Supplementary Fig. 1).

\section{Data analysis:}

Prior to data analysis, rare taxa (with a maximum abundance less than 5\%) and those that occurred in less than 5 samples were removed (Amesbury et al., 2013). Ordination analyses were carried out using the 'vegan' package (Oksanen et al., 2015) in R version 3.0.2 (R Core Team, 2013) to explore the data and the relationship between the environmental factos ( 57 measurements of WTD, moisture content, $\mathrm{EC}, \mathrm{pH}$ ) and testate amoebae. We first used detrended correspondence analysis (DCA) to analyse the gradient length of the primary ordination axis to determine whether the response curve was linear or unimodal (Birks et al., 2012). Our gradient length (3.54 SD) suggested that the underlying response curve for testate amoebae was unimodal, and hence canonical correlation analysis (CCA) was selected for further analysis. Monte Carlo permutations (1000 iterations) were used to test statistical significance. Stepwise regression and variation partition were conducted to evaluate the explanatory power of the environmental variables and to identify the primary determinant of the testate amoebae assemblage. We also used a ratio of the first constrained to the first unconstrained eigenvalue $(\lambda 1 / \lambda 2)$ in our CCA with only one explanatory variable to assess the explanatory power of the environmental variables (Juggins, 2013).

A total of 68 samples were available for the development of the transfer functions. We used the 'rioja' package (Juggins, 2014) in R to build transfer functions, including Weighted Average (WA), Weighted Average with tolerance down-weighting (WA.Tol), Weighted Average Partial Least Squares (WAPLS), Modern Analogue Technique (MAT) and Maximum Likelihood (ML). We used the identifiers '.cla' and '.inv' for classical and inverse deshrinking methods, respectively, for WA and WA.Tol.

In addition to these 'all-species' transfer functions, based on the entire dataset (minus rare taxa), we also developed species-pruned transfer functions. This follows, Juggins et al. (2015), who described excluding non-informative taxa, which degrade predictive ability, based on the importance of individual taxa as predictors of the variable of interest, in this case WTD. For this, an importance index was calculated for the taxa based on the "randomPTF" function in the "rioja" package. We used the absolute value of the difference between the prediction errors for the modified and original out-of-bag data instead of just the difference, because some of differences were found to be negative. It should be noted that the taxa importance index can only be used to compare taxa within the same transfer function. Backward stepwise selection was used to remove non-informative taxa according to the importance index and a transfer function was derived with the lowest root mean squared error of prediction (RMSEP), following Juggins et al. (2015). For simplicity, the lowest RMSPE was chosen as the criteria, without considering statistical significant difference among adjacent data points. 
We also removed outlying samples before deriving our final transfer functions: outliers were identified as samples with a residual value $>20 \%$ of the range of WTD across our sites $(14 \mathrm{~cm})$, following the commonly recently applied (Swindles et al., 2009; Amesbury et al., 2013; 2016) datascreening method of Birks et al. (1990).

The mathematical basis and the use of different transfer functions have been discussed in detail by Birks et al. (2012). The performance of our models was initially evaluated using RMSEP with leaveone-out (LOO) cross validation, $\mathrm{R}^{2}$, average bias (Ave.Bias) and maximum bias (Max.Bias). Max.Bias is the largest absolute value of the Ave.Bias during the cross-validation cycle and can represent the over- or under-estimation tendency along particular parts of the gradient. As LOO and bootstrap cross-validation may underestimate RMSEP, other statistical evaluations, including leave-one-site-

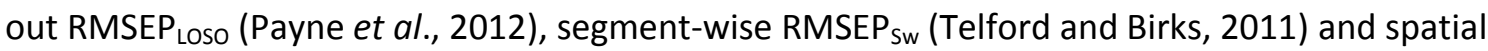
autocorrelation analysis were considered following recommendations by Amesbury et al. (2013). Spatial autocorrelation analysis was carried out using the 'palaeoSig' package (Telford, 2015). Due to the clustered spatial distribution of our testate amoebae dataset, traditional bootstrap methods are inappropriate; therefore cluster-bootstrap RMSEP ${ }_{C B}$ was adopted (Payne et al., 2012).

\section{Results:}

\section{Ecology of testate amoebae}

Supplementary Table 2 provides a list of the testate amoebae that we identified across all sites. A total of 50 taxa were identified in the south-eastern Australian sites sampled and 10 of these were considered rare using our criteria. The most common taxa encountered were Pseudodifflugia fulva type, Centropyxis platystoma type, Euglypha tuberculate type, P. griseola type, Trinema/Corythion type, Heleopera sylvatica, Assulina muscorum and Cyclopxis arcelloides type (Fig. 2). We found some taxa that are exclusive to the Southern Hemisphere and others, such as Certesella martiali and Apodera vas, that have a distinctly Gondwanic distribution (van Bellen et al., 2014), although they have been found just beyond these land masses, presumably associated with dispersal (e.g. Smith et al., 2008; Heger et al., 2011).

The CCA identified that the environmental variables account for $18 \%$ of the total variance (Supplementary Table 3, with constrained proportion in Supplementary Table 3a). CCA axis 1 (eigenvalue $=0.40$ ) and CCA axis 2 (eigenvalue $=0.20$ ) are both significant $(P<0.001$ ) using Monte Carlo permutations, and account for $87 \%$ of explained variance (constrained). The principal axis (CCA 1 ) is clearly associated with WTD, suggesting that WTD is the primary environmental variable controlling testate amoebae community composition (Fig. 3). This means that the distribution of taxa along CCA 1 is very similar to the rank order of optima WTD of the testate amoebae derived from a WA model (Fig. 4).

High values on CCA 1 represent dry conditions (high WTD), and hence dry samples (e.g. CC, TCB7, DC4) and dry-indicating taxa (e.g. Trigonopyxis arcula type, Cyclopyxis arcelloides type and $A$. 
muscorum) appear at the right edge of CCA 1 , whereas low values on CCA 1 represent wet microsites (e.g. BF5, BF6 and RG8) and wet-indicating taxa (e.g. Centropyxs ecornis type and Nebela retorta).

Stepwise regression also identified WTD and EC as significant explanatory variables. Variance partitioning found that WTD contributed the most to the explained variance with $57.08 \%$ and EC contributed $22.70 \%$. The joint contribution between WTD and the other environmental variables (EC, moisture content and $\mathrm{pH}$ ) ranged from 0 to $2.47 \%$, indicating the contribution of WTD (57.08\%) is mostly independent. The ratio $\lambda 1 / \lambda 2$ for WTD was close to 1 (0.95), and for EC it was 0.31 . These results clearly support the hypothesis that there is a significant relationship between WTD and testate amoebae, with little confounding interaction between WTD and the other environmental variables. They strongly support the development of a transfer function between WTD and testate amoebae.

The relationship between different taxa and WTD was further assessed using an importance index (Supplementary Fig. 2) (Juggins et al., 2015). The numeric value of the importance index, describing how important a taxon is (with larger values describing more important taxa), may be slightly different for each run as the index is calculated by permutation for each run. Nonetheless, this importance index can provide a new approach to rank the relative importance for these taxa. $A$. muscorum, $C$. platystoma type, $C$. arcelloides type, Difflugia pritist type and $P$. fulva type were identified as the most important taxa responding to WTD across the five different transfer functions, except ML.

(insert Fig. 2 near here)

(insert Fig. 3 near here)

(insert Fig. 4 near here)

\section{Transfer functions}

The performance of the common transfer functions are shown in Table 2, including results based on LOO and cluster-bootstrap cross-validation. Their performance was improved (to an $\mathrm{R}^{2}$ above 0.8 ) after removal of outlier samples, with RMSEP reduced from $\sim 9 \mathrm{~cm}$ to $\sim 7 \mathrm{~cm}$. WAPLS with one component was identified as the optimal WAPLS, which is exactly the same as WA.inv (Birks, 2012) and so was omitted from further analyses (Table 2). Under LOO cross-validation (Table 2), MAT ( $k=4$ ), WA.cla and WA.inv were the three best transfer functions based on RMSEP LOO $_{\text {and }}{ }^{2}$ while MAT, WA.cla and $M L$ were the three best transfer functions under cluster-bootstrap cross-validation (Supplementary Table 4). Based on these results WA.cla was chosen to represent the weighted averaging family and MAT and ML were analysed further to evaluate a different family-type of transfer functions. The results based on cluster-bootstrap were identical to those based on LOO and will not be discussed further. It should be noted that traditional bootstrapping suggested that $\mathrm{ML}$ 
outperformed MAT (details not shown). Scatter plots in Supplementary Fig. 3 show almost all observations fell within the threshold for removing outliers $(14 \mathrm{~cm})$.

(insert Table 2 near here)

All RMSEP (LOO, SW and LOSO) values were considerably lower than the standard deviation of WTD (Table 2), suggesting that all models have an adequate predictive capacity. The ranges in Table 2 are

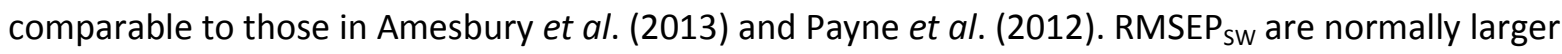

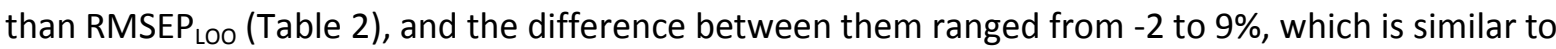
the range of RMSEP SW $_{\text {in }}$ Amesbury et al. (2013). All three models have relative lower RMSEP in the wet segments (WTD<30 cm), which has a higher frequency of samples, and higher RMSEP in the dry segments where samples were fewer (Supplementary Fig. 4). RMSEP Loso are normally larger than RMSEP $_{\text {Loo }}$ for the transfer functions, suggesting that the transfer functions are influenced by the clustered nature of the testate amoebae dataset. The exception is MAT where RMSEP Loso has a $-8 \%$ decrease (Table 2) which suggests that in our dataset MAT does not suffer from this bias, a conclusion supported by the spatial autocorrelation analysis (Supplementary Fig. 5).

Supplementary Fig. 5 shows the spatial autocorrelation among samples when removing samples randomly or within certain geographic neighbourhoods. If spatial autocorrelation is not a problem then the deletion of geographical neighbours should follow similar trajectories derived from random deletions, with dramatic declines in $\mathrm{R}^{2}$ normally found (Telford and Birks, 2011). $\mathrm{R}^{2}$ for WA.cla, MAT and $\mathrm{ML}$ always remained stable and closely followed the trend of random deletions when geographic neighbours were deleted. Therefore, in our dataset it seems there is negligible spatial autocorrelation for the developed transfer functions.

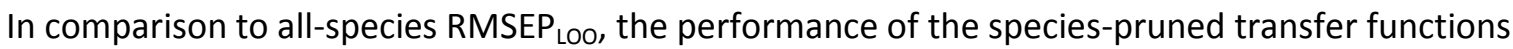
(Table 3) are similar (using RMSEP and $\mathrm{R}^{2}$ ). A selection of optimal species-pruned transfer functions are shown in Fig. 5, from which it is clear that using only those taxa that were important to WTD had variable effects on RMSEP. The optimal species-pruned MAT was developed with 17 taxa and is the best performing species-pruned transfer function, with the RMSEP Loo (5.97) larger than that of the all-species MAT (5.75). The species-pruned MAT suffered, however, from segment-wise bias with a


only 10 taxa removed, but resulted in the worst performance. The species-pruned ML transfer function also had an unstable rank order of taxa importance when 'randomPTF' was run several times, whereas the other transfer functions had a relative stable ranked importance of taxa.

(insert Table 3 near here)

(insert Fig. 5 near here) 


\section{Ecology of testate amoebae in south-eastern Australia}

The most common testate amoebae in the peatlands in south-eastern Australia are $C$. arcelloides type, $C$. platystoma type and $A$. muscorum: this has some overlap with the common taxa found in New Zealand which also included A. muscorum but Charman (1997) and Wilmshurst et al. (2003) also commonly found Euglypha rotunda type and $P$. fulva type. E. rotunda type is one of the least common taxa in our samples, but $E$. tuberculata type was very common. $C$. aculeate type, $C$. ecornis type, Nebela barbata and Quadrulella symmetrica were also identified in our samples but were not found by Charman (1997) and Wilmshurst et al. (2003) in New Zealand, although both taxa have been previously identified in south-eastern Australia (Meisterfeld and Tan, 1998) and New Zealand (Bamforth, 2015). Alcodera cockayni has previously been identified in New Zealand (Charman, 1997; Wilmshurst et al., 2002) and Tasmania (Bamforth, 2015) but has not been encountered in (mainland) south-eastern Australia before. The presence of $Q$. symmetrica is likely to reflect the minerotrophic nature of these peatlands in Australia, as they are absent in truly rain-fed ombrotrophic bogs (Meisterfeld and Tan, 1998). Our identification of N. retorta was a first for Australia, but it has been reported in New Zealand (Bamforth, 2015).

A. muscorum is common in both the Northern (Amesbury et al., 2016) and Southern Hemisphere (Charman, 1997; Wilmshurst et al., 2002; van Bellen et al., 2014) but other common taxa in the Northern Hemisphere, such as Archerella flavum and Amphitrema wrightianum, were absent in Patagonia (van Bellen et al., 2014) and south-eastern Australia (Meisterfeld and Tan, 1998) while $A$. wrightianum was discovered only in a few samples in New Zealand (Charman, 1997; Bamforth, 2015). Hyalosphenia subflava, found in sub-fossil samples in the Northern Hemisphere, but absent from modern analogues, were in both our modern surface samples and in Patagonia (van Bellen et al., 2014). A. vas and C. martiali were the two most common Gondwana-specific taxa but may only have a limited distribution within the Gondwanic landmasses (Smith et al., 2008).

The testate amoebae in our south-eastern Australian samples have similar moisture niches with those from other regions (Fig. 4). C. aculeate type and Arcella discoides type are invariability found in the wetter WTD samples (van Bellen et al., 2014; Swindles et al., 2014). A. muscorum, C. arcelloides type, $H$. subflava and $T$. arcula type are also commonly considered as dry indicators. One difference identified was E. tuberculata type and Trinema/Corythion type, which are generally associated with drier conditions (van Bellen et al., 2014) while they were intermediate-dry indicators in our research.

The CCA, stepwise regression and variation partition results all supported a strong, significant relationship between WTD and testate amoebae, and that WTD is the primary environmental variable controlling their community composition. Environmental variables explained $18 \%$ of the 

(Payne et al., 2008) and more than 50\% explained in bogs in England (Woodland et al., 1998). There is large portion of taxon variance that remained unexplained in our samples, and this might be related to environmental variables that were not considered or to ecological variability of testate amoebae.

It should be noted that although there is a significant statistical relationship between WTD and testate amoebae, it is possible that any reconstruction based on the variance of testate amoebae assemblages might fail to reflect the true variance of WTD. Any reconstruction reflects the whole signal, in this case, everything that influences testate amoebae composition, including habitat, light, food availability etc. (Mitchell et al., 2008) rather than the independent signal alone (WTD). Juggins (2013) suggested one way to test if a variable is ecologically important is to compare the optimal rank of different taxa across different regions, because the biological response should not change if the reconstructed variable is important. We found that the optimal WTD for different testate amoebae was similar to those in other regions.

The importance index of the taxa (Supplementary Fig. 2) offers another useful insight into the relationship between individual taxa and WTD, in terms of relative importance rank for taxa. Several taxa, such as $A$. muscorum, $C$. platystoma type, $C$. arcelloides type, $D$. pritist type and $P$. fulva were identified as the most important taxa relating to WTD. If these taxa were a significant component of the testate assemblage in a fossil assemblage then we could be more confident of any reconstructed WTD over that time period. This suggests that the degree of overlap between fossil taxa and highly ranked taxa in an importance index could be used to complement the confidence of reconstructed WTD. Our segment wise analyses (Supplementary Fig. 4) show that our prediction of WTD is less robust in drier segments, and hence we would need to be slightly more cautious about any palaeoenvironmental reconstruction in drier times. The instrumental comparison work by Swindles et al. (2015) leads to similar conclusions: there are likely to be times in any palaeo-environmental reconstruction of moisture based on testate amoebae when we can have more or less confidence in the results.

Juggins (2013) also recommended avoiding reconstructing variables with a small independent component of the variance and, instead, to look at independent and shared variance by hierarchical partitioning or constrained ordination with all significant variables. We found that the shared component of variance ranged from 0 to $2.48 \%$ for WTD and the other environmental variables, and that WTD contributed more than a half $(57.08 \%)$ of the explained partition. Finally, $\lambda 1 / \lambda 2$ is another useful index as a value greater than 1.0 indicates that a variable of interest can represent an important ecological gradient (Ter Braak and Smilauer, 1998). In our study $\lambda 1 / \lambda 2$ was 0.95 for WTD, which is higher than is often reported in published research (Juggins, 2013).

Together these results suggest that testate amoebae are a sensitive proxy of WTD in south-eastern 
Leave-one-out (LOO) cross-validation is the most common method to evaluate the performance of different transfer functions. Another less common method is traditional bootstrap cross-validation, which although often performs worse than LOO, is thought to be more realistic (Birks et al., 2012). Due to the clustered nature of our dataset, cluster-bootstrap cross-validation ( $\mathrm{RMSEP}_{\mathrm{CB}}$ ) was tested in this research, as this addressed any bias in traditional bootstrap cross-validation, which suggested that ML outperformed MAT. As LOO and traditional bootstrap cross-validation are likely to give an over-optimistic evaluation, they were supplemented by segment-wise (RMSEP $\left.P_{S W}\right)$, leave-one-site-out

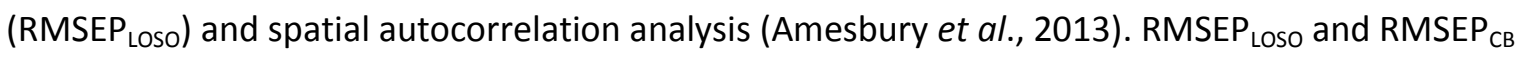
(Table 2) confirmed that MAT was the best performing transfer function. This supports the claim that RMSEP LOSO is sufficient to distinguish biases related to clustered data by Payne et al. (2012). It seems that the transfer functions based on all species (except rare taxa) developed in this research were only negligibly affected by spatial autocorrelation (Supplementary Fig. 5).

It has been argued that species-pruned models can increase the predictive robustness of transfer functions (Juggins et al. 2015), which is a sensible proposition as non-informative taxa are excluded. Our evaluation of the species-pruned transfer functions found that they performed similarly to the all-species transfer functions (Table 3). It should be noted however that in this study the all-species transfer functions were calculated after the removal of 10 rare taxa, and the further removal of the least 10 non-informative taxa did not improve RMSEP (Fig. 5). This implies that the strategy to remove rare species at the beginning for our all-species transfer functions was appropriate. Despite no great increase in predictive performance, the use of species-pruned models provided a useful consideration of the importance of taxa and their influence on the development of different transfer functions.

In this study our RMSEP LOO $_{\text {RMSEP }}$ SW, RMSEP LOSO, RMSEP $_{C B}$ results for all-species (except rare taxa) and species-pruned methods all suggest that the modern analogue technique (MAT) is the best transfer function. In previous studies MAT has rarely been the preferred model type, with weighted averaging-based models generally having the best performance (Hughes et al., 2006; Payne et al., 2008; Amesbury et al., 2013; 2016). It is only usually when there is a strong spatial autocorrelation bias that MAT outperforms other model types (Telford and Birks, 2009). MAT is also sensitive to uneven sampling (Telford and Birks, 2011). In contrast, in this study MAT has an acceptable RMSEP $P_{S W}$,

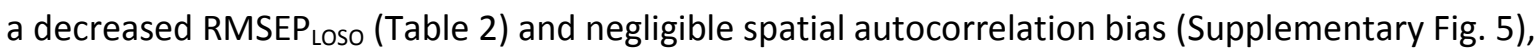
suggesting the performance of MAT is not biased by spatial autocorrelation. Under the speciespruned method, only the most important 18 informative-taxa were included for MAT, and this interplay between importance and rarity might be the reason why MAT is robust to spatial autocorrelation in this study.

Other commonly applied model types performed poorly for this dataset. WA.cla might be over-fitted as 14 observations were removed during data-screening (Table 2). Although $\mathrm{ML}$ is considered to be the most statistically-sound transfer function (Birks et al., 2012), robust to spatial autocorrelation and uneven sampling and less sensitive to the potential confounding effects of other environmental variables (Juggins et al., 2015), it also performed poorly. Notably, ML considers almost every taxa in the dataset as informative (Table 3 ), despite some of them being rare ( $<5$ occurrences and max abundance $<5 \%$ ) and the optimal WTD for these rare taxa was not very stable. For better performance in south-eastern Australia ML may require a larger (modern) dataset. 
It should be noted that the performance of MAT for the reconstruction of WTD might still suffer if there is considerable difference between the testate amoebae in modern samples and those recovered from sediment cores. In New Zealand Wilmshurst et al. (2003) identified such a disparity and this might potentially reflect the poor preservation of testate amoebae in Australasia or different assemblages under different moisture conditions. This means that consideration of this overlap (between modern and sub-fossil) is necessary, and other transfer functions, such as allspecies WA.cla or species-pruned WA.inv might be an alternative.

\section{Conclusions}

This research offers insight into the ecology of testate amoebae in south-eastern Australia and describes the development of transfer functions for the reconstruction of water-table depth (WTD). In conclusion:

1. A total of 50 taxa were recorded in 68 samples from 8 high-altitude bogs and fens in south-eastern Australia. The most common taxa were E. tuberculata type, C. platystoma type, A. muscorum, Trinema/Corythion type and C. platystoma type. A. vas, both Gondwanic endemic taxa, were discovered in about half of our samples and we recorded the occurrence of $N$. retorta for the first time in Australia.

2. WTD was the significant primary environmental variable determining the testate amoeba community composition. WTD contributed more than a half (57.08\%) of the explained variance of the testate amoebae community, with little (0 to $2.48 \%$ ) shared contribution with other environmental variables. A ratio of the first constrained to the first unconstrained eigenvalue in a canonical correlation analysis $(\lambda 1 / \lambda 2)$ also suggested that WTD was an ecologically important variable. These results mean that we could confidently reconstruct a robust and reliable transfer function between testate amoebae and WTD.

3. We developed all-species and species-pruned transfer functions and demonstrated a statistically sound performance, with $R^{2}$ values of around 0.8 and RMSEP values of approximately $7 \mathrm{~cm}$. Results from all-species and species-pruned models suggest that the modern analogue technique (MAT) is the best transfer function, with negligible bias from uneven sampling and spatial autocorrelation. This transfer function is provided in the Supplementary Information. Although we advocate using all(minus rare) species MAT as the recommended transfer function to reconstruct WTD in southeastern Australia, the species-pruned MAT transfer function also allows a useful consideration of the importance of each taxa of testate amoebae for WTD, and this can be used to better evaluate the performance of a transfer function in any palaeo-environmental reconstruction of WTD. 
This research was funded (to SM and GH) by the Temperate Highland Peat Swamps on Sandstone Research Program (THPSS Research Program) administered by the Australian National University. We thank the NSW National Parks \& Wildlife Service and ACT Parks, Conservation and Lands for facilitating access and sampling in their reserves. The introduction of acetone into our testate amoebae preparation protocol resulted from discussion with Associate Professor Jason Harper (UNSW Australia). We also thank Dr Benedict Keaney for his assistance with field sampling, Associate Professor Richard Telford (University of Bergen, Norway) for his comments on our results and Dr Tom Roland (University of Exeter) for taxonomic help. We are grateful to two anonymous reviewers whose thoughtful comments helped improve this paper.

\section{References:}

Amesbury, M.J., Mallon, G., Charman, D.J., Hughes, P.D.M., Booth, R.K., Daley, T.J., Garneau, M., 2013. Statistical testing of a new testate amoeba-based transfer function for water-table depth reconstruction on ombrotrophic peatlands in north-eastern Canada and Maine, United States. Journal of Quaternary Science 28, 27-39.

Amesbury, M.J., Swindles, G.T., Bobrov, A., Charman, D.J., Holden, J., Lamentowicz, M., Mallon, G., Mazei, Y., Mitchell, E.A.D., Payne, R.J., Roland, T.P., Turner, T.E., Warner, B.G., 2016. Development of a new pan-European testate amoeba transfer function for reconstructing peatland palaeohydrology. Quaternary Science Reviews 152, 132-151.

Australian Bureau of Meteorology, 2016. Annual rainfall - Southeastern Australia (1990-2016). Available at: http://www.bom.gov.au/climate/change/index.shtml\#tabs=Tracker\&tracker=timeseries\&tQ =graph\%3Drain\%26area\%3Dseaus\%26season\%3D0112\%26ave yr\%3D7.

Ayliffe, L.K., Marianelli, P.C., Moriarty, K.C., Wells, R.T., McCulloch, M.T., Mortimer, G.E., Hellstrom, J.C., 1998. 500 ka precipitation record from southeastern Australia: Evidence for interglacial relative aridity. Geology 26, 147-150.

Bamforth, S.S., 2015. Composition of Soil Testate Amoebae Communities: Their Structure and Modifications in the Temperate Rain Forests of New Zealand and Tasmania. Journal of Eukaryotic Microbiology 62, 217-226.

Barnett, R.L., Charman, D.J., Gehrels, W.R., Saher, M.H., Marshall, W.A., 2013. Testate Amoebae as Sea-level Indicators in Northwestern Norway: Developments in Sample Preparation and Analysis. Acta Protozoologica 52, 115-128.

Birks, H., Line, J., Juggins, S., Stevenson, A., Ter Braak, C., 1990. Diatoms and pH reconstruction. Philosophical Transactions of the Royal Society B: Biological Sciences 327, 263-278.

Birks, H.J.B., Lotter, A.F., Juggins, S., Smol, J.P., 2012. Tracking Environmental Change Using Lake Sediments: Data Handling and Numerical Techniques. Springer Science \& Business Media.

Black, M.P., Mooney, S.D., Attenbrow, V., 2008. Implications of a 14200 year contiguous fire record for understanding human-climate relationships at Goochs Swamp, New South Wales, Australia. The Holocene 18, 437-447.

Booth, R., Lamentowicz, M., Charman, D., 2010. Preparation and analysis of testate amoebae in peatland paleoenvironmental studies. Mires and Peat. 
Bowler, J.M., Hamada, T., 1971. Late Quaternary Stratigraphy and Radiocarbon Chronology of Water Level Fluctuations in Lake Keilambete, Victoria. Nature 232, 330-332.

Charman, D.J., 1997. Modelling hydrological relationships of testate amoebae (Protozoa: Rhizopoda) on New Zealand peatlands. Journal of the Royal Society of New Zealand 27, 465-483.

Charman, D.J., Blundell, A., Members, A., 2007. A new European testate amoebae transfer function for palaeohydrological reconstruction on ombrotrophic peatlands. Journal of Quaternary Science 22, 209-221.

Charman, D.J., Gehrels, W.R., Manning, C., Sharma, C., 2010. Reconstruction of recent sea-level change using testate amoebae. Quaternary Research 73, 208-219.

Charman, D.J., Hendon, D., Woodland, W.A., 2000. The identification of testate amoebae (Protozoa: Rhizopoda) in peats. Quaternary Research Association.

Cook, E.J., van der Kaars, S., 2006. Development and testing of transfer functions for generating quantitative climatic estimates from Australian pollen data. Journal of Quaternary Science 21, 723-733.

CSIRO, 2010. Climate variability and change in south-eastern Australia: A synthesis of findings from Phase 1 of the South Eastern Australian Climate Initiative (SEACI).

Delworth, T.L., Zeng, F., 2014. Regional rainfall decline in Australia attributed to anthropogenic greenhouse gases and ozone levels. Nature Geosci 7, 583-587.

Faegri, K., Iversen, J., 1964. Textbook of Pollen Analysis:(former Title: Textbook of Modern Pollen Analysis). Munksgaard.

Gergis, J., Gallant, A.J.E., Braganza, K., Karoly, D.J., Allen, K., Cullen, L., D’Arrigo, R., Goodwin, I., Grierson, P., McGregor, S., 2012. On the long-term context of the 1997-2009 'Big Dry' in South-Eastern Australia: insights from a 206-year multi-proxy rainfall reconstruction. Climatic Change 111, 923-944.

Hazell, Z.J., 2004. Holocene Palaeoclimate Reconstruction From New Zealand Peatlands. University of Plymouth.

Heger, T.J., Lara, E. and Mitchell, E.A.D., 2011. Arcellinida testate amoebae (Arcellinida: Amoebozoa): model of organisms for assessing microbial biogeography, in: Fontaneto, D. (Ed.), The importance of being small: does size matter in biogeography? Cambridge University Press, pp. 111-129.

Holden, J., Wallage, Z.E., Lane, S.N., McDonald, A.T., 2011. Water table dynamics in undisturbed, drained and restored blanket peat. Journal of Hydrology 402, 103-114.

Hope, G., Nanson, R., Jones, P., 2012. Peat-Forming Bogs and Fens of the Snowy Mountains of NSW. Technical Report. Office of Environment and Heritage, Sydney South.

Hughes, P.D.M., Blundell, A., Charman, D.J., Bartlett, S., Daniell, J.R.G., Wojatschke, A., Chambers, F.M., 2006. An 8500cal. year multi-proxy climate record from a bog in eastern Newfoundland: contributions of meltwater discharge and solar forcing. Quaternary Science Reviews 25, 1208-1227.

Jones, R.N., McMahon, T.A., Bowler, J.M., 2001. Modelling historical lake levels and recent climate change at three closed lakes, Western Victoria, Australia (c.1840-1990). Journal of Hydrology 246, 159-180.

Juggins, S., 2013. Quantitative reconstructions in palaeolimnology: new paradigm or sick science? Quaternary Science Reviews 64, 20-32.

Juggins, S., 2014. rioja: Analysis of Quaternary Science Data, R package version (0.9-3).

Juggins, S., Simpson, G.L., Telford, R.J., 2015. Taxon selection using statistical learning techniques to improve transfer function prediction. The Holocene 25, 130-136.

Kemp, J., Rhodes, E.J., 2010. Episodic fluvial activity of inland rivers in southeastern Australia: Palaeochannel systems and terraces of the Lachlan River. Quaternary Science Reviews 29, 732-752. 
Kemp, J., Spooner, N.A., 2007. Evidence for regionally wet conditions before the LGM in southeast Australia: OSL ages from a large palaeochannel in the Lachlan Valley. Journal of Quaternary Science 22, 423-427.

McGlone, M.S., Wilmshurst, J.M., 1999. A Holocene record of climate, vegetation change and peat bog development, east Otago, South Island, New Zealand. Journal of Quaternary Science 14, 239-254.

McGowan, H.A., Marx, S.K., Denholm, J., Soderholm, J., Kamber, B.S., 2009. Reconstructing annual inflows to the headwater catchments of the Murray River, Australia, using the Pacific Decadal Oscillation. Geophysical Research Letters 36, n/a-n/a.

Meisterfeld, R., Tan, L.-W., 1998. First records of Testate Amoebae (Protozoa: Rhizopoda) from Mount Buffalo National Park, Victoria: preliminary notes.

Mitchell, E.A.D., Charman, D.J., Warner, B.G., 2008. Testate amoebae analysis in ecological and paleoecological studies of wetlands: past, present and future. Biodiversity and Conservation 17, 2115-2137.

Oksanen, J., Kindt, R., Legendre, P., O'Hara, B., Simpson, G.L., Solymos, P., Stevens, M.H.H., Wagner, H., 2015. vegan: Community Ecology Package. R package version 2.2-1.

Palmer, J.G., Cook, E.R., Turney, C.S., Allen, K., Fenwick, P., Cook, B.I., O'Donnell, A., Lough, J., Grierson, P., Baker, P., 2015. Drought variability in the eastern Australia and New Zealand summer drought atlas (ANZDA, CE 1500-2012) modulated by the Interdecadal Pacific Oscillation. Environmental Research Letters 10, 124002.

Payne, R.J., 2011. Can testate amoeba-based palaeohydrology be extended to fens? Journal of Quaternary Science 26, 15-27.

Payne, R.J., Charman, D.J., Matthews, S., Eastwood, W.J., 2008. Testate amoebae as palaeohydrological proxies in Surmene Agacbasi Yaylasi peatland (Northeast Turkey). Wetlands 28, 311-323.

Payne, R.J., Mitchell, E.A.D., 2007. Ecology of testate amoebae from mires in the central Rhodope Mountains, Greece and development of a transfer function for palaeohydrological reconstruction. Protist 158, 159-171.

Payne, R.J., Mitchell, E.A.D., 2009. How many is enough? Determining optimal count totals for ecological and palaeoecological studies of testate amoebae. J Paleolimnol 42, 483-495.

Payne, R.J., Telford, R.J., Blackford, J.J., Blundell, A., Booth, R.K., Charman, D.J., Lamentowicz, L., Lamentowicz, M., Mitchell, E.A.D., Potts, G., Swindles, G.T., Warner, B.G., Woodland, W., 2012. Testing peatland testate amoeba transfer functions: Appropriate methods for clustered training-sets. The Holocene 22, 819-825.

RCoreTeam, 2013. R Core Team (2013). R: A language and environment for statistical computing. $R$ Foundation for Statistical Computing, Vienna, Austria. URL http://www.R-project.org/.

Smith, H.G., Bobrov, A., Lara, E., 2008. Diversity and biogeography of testate amoebae. Biodiversity and Conservation 17, 329-343.

Sullivan, M., Booth, R., 2007. Key of testate amoebae inhabiting Sphagnum-dominated peatlands with an emphasis on taxa preserved in Holocene sediments. Lehigh University, Bethlehem.

Swindles, G.T., Charman, D.J., Roe, H.M., Sansum, P.A., 2009. Environmental controls on peatland testate amoebae (Protozoa: Rhizopoda) in the North of Ireland: Implications for Holocene palaeoclimate studies. J Paleolimnol 42, 123-140.

Swindles, G.T., Holden, J., Raby, C.L., Turner, T.E., Blundell, A., Charman, D.J., Menberu, M.W., Kløve, B., 2015. Testing peatland water-table depth transfer functions using high-resolution hydrological monitoring data. Quaternary Science Reviews 120, 107-117.

Swindles, G.T., Lamentowicz, M., Reczuga, M., Galloway, J.M., 2016. Palaeoecology of testate amoebae in a tropical peatland. European Journal of Protistology 55, Part B, 181-189.

Swindles, G.T., Reczuga, M., Lamentowicz, M., Raby, C.L., Turner, T.E., Charman, D.J., Gallego-Sala, A., Valderrama, E., Williams, C., Draper, F., Coronado, E.N.H., Roucoux, K.H., Baker, T., Mullan, 
D.J., 2014. Ecology of Testate Amoebae in an Amazonian Peatland and Development of a Transfer Function for Palaeohydrological Reconstruction. Microbial Ecology 68, 284-298.

Telford, R.J., 2015. palaeoSig: Significance Tests of Quantitative Palaeoenvironmental Reconstructions, $R$ package version (1.1-3).

Telford, R.J., Birks, H.J.B., 2009. Evaluation of transfer functions in spatially structured environments. Quaternary Science Reviews 28, 1309-1316.

Telford, R.J., Birks, H.J.B., 2011. Effect of uneven sampling along an environmental gradient on transfer-function performance. J Paleolimnol 46, 99-106.

Ter Braak, C., Smilauer, P., 1998. CANOCO reference manual and User's guide to Canoco for windows: software for canonical community ordination (version 4.5) Cajo JF ter Braak and Petr Smilauer. Centre for Biometry.

Timbal, B., Fawcett, R., 2013. A Historical Perspective on Southeastern Australian Rainfall since 1865 Using the Instrumental Record. Journal of Climate 26, 1112-1129.

van Bellen, S., Mauquoy, D., Payne, R.J., Roland, T.P., Daley, T.J., Hughes, P.D.M., Loader, N.J., StreetPerrott, F.A., Rice, E.M., Pancotto, V.A., 2014. Testate amoebae as a proxy for reconstructing Holocene water table dynamics in southern Patagonian peat bogs. Journal of Quaternary Science 29, 463-474.

Verdon-Kidd, D.C., Kiem, A.S., 2009. Nature and causes of protracted droughts in southeast Australia: Comparison between the Federation, WWII, and Big Dry droughts. Geophysical Research Letters 36, n/a-n/a.

Whinam, J., Hope, G., Clarkson, B., Buxton, R., Alspach, P., Adam, P., 2003. Sphagnum in peatlands of Australasia: Their distribution, utilisation and management. Wetlands Ecology and Management 11, 37-49.

Wilkins, D., Gouramanis, C., De Deckker, P., Fifield, L.K., Olley, J., 2013. Holocene lake-level fluctuations in Lakes Keilambete and Gnotuk, southwestern Victoria, Australia. The Holocene 23, 784-795.

Wilmshurst, J.M., McGlone, M.S., Charman, D.J., 2002. Holocene vegetation and climate change in southern New Zealand: Linkages between forest composition and quantitative surface moisture reconstructions from an ombrogenous bog. Journal of Quaternary Science 17, 653666.

Wilmshurst, J.M., Wiser, S.K., Charman, D.J., 2003. Reconstructing Holocene water tables in New Zealand using testate amoebae: differential preservation of tests and implications for the use of transfer functions. The Holocene 13, 61-72.

Woodland, W.A., 1996. Holocene palaeohydrology from testate amoebae analysis : developing a model for British peatlands. University of Plymouth,UK.

Woodland, W.A., Charman, D.J., Sims, P.C., 1998. Quantitative estimates of water tables and soil moisture in Holocene peatlands from testate amoebae. The Holocene 8, 261-273. 


\section{Figures:}

Figure 1: Location of sites (red circles) where modern samples were taken for developing the relationship between testate amoebae and water-table depth. ACT = Australian Capital Territory. For details on each site see Table 1.

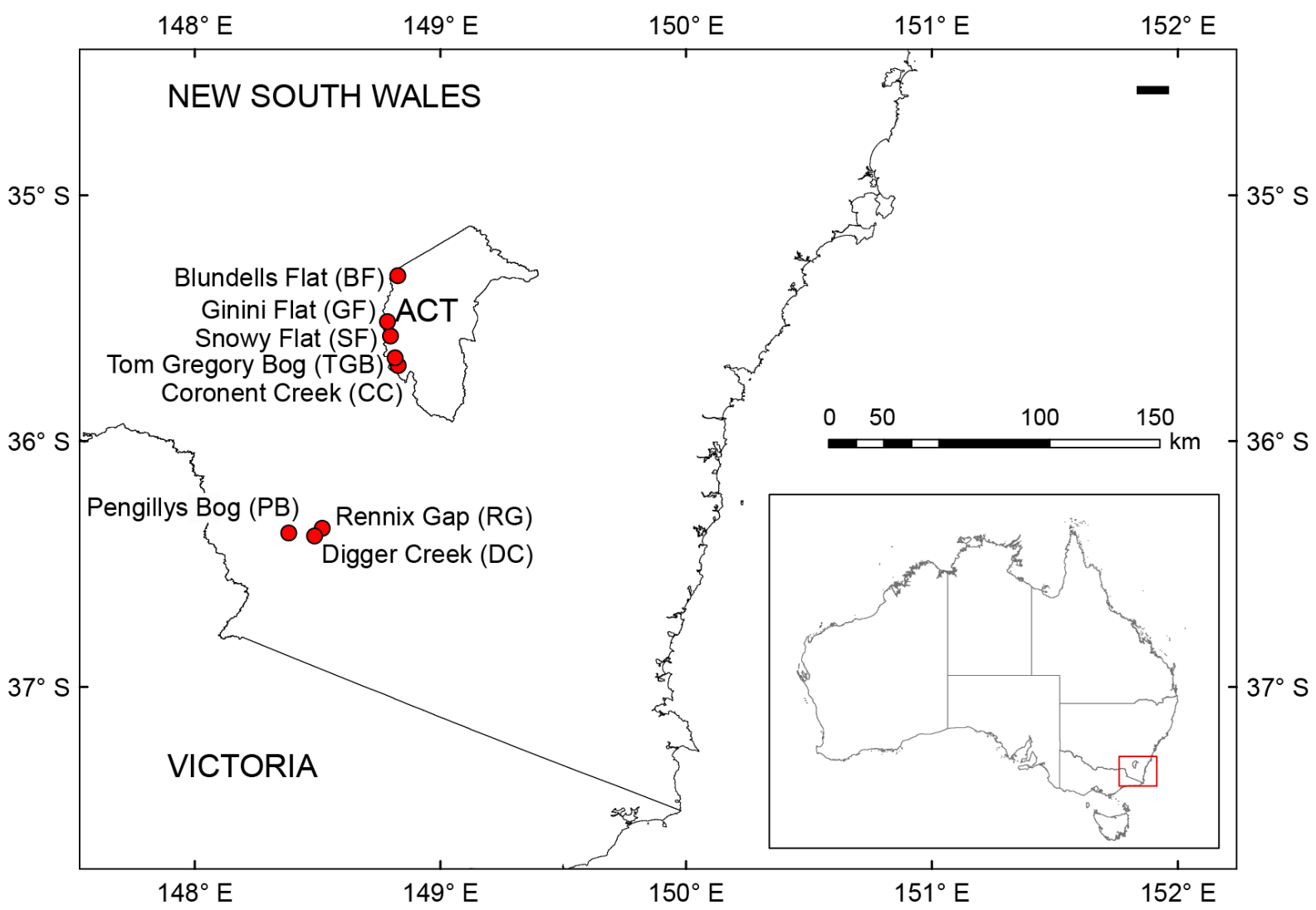


Figure 2: Abundance of testate amoebae in modern surface samples, shown as percentages of the total count. The $y$-axis represents the 68 modern samples from eight sites (see Table 1 for site details). Testate amoebae are ordered from "wet" on the left to "dry" on the right based on the optima from the weighted average (classical deshrinking WA.cla) transfer function (see also Figure 4). Water-table depth plot shows the measured water table value $(\mathrm{cm})$ of each individual sample.

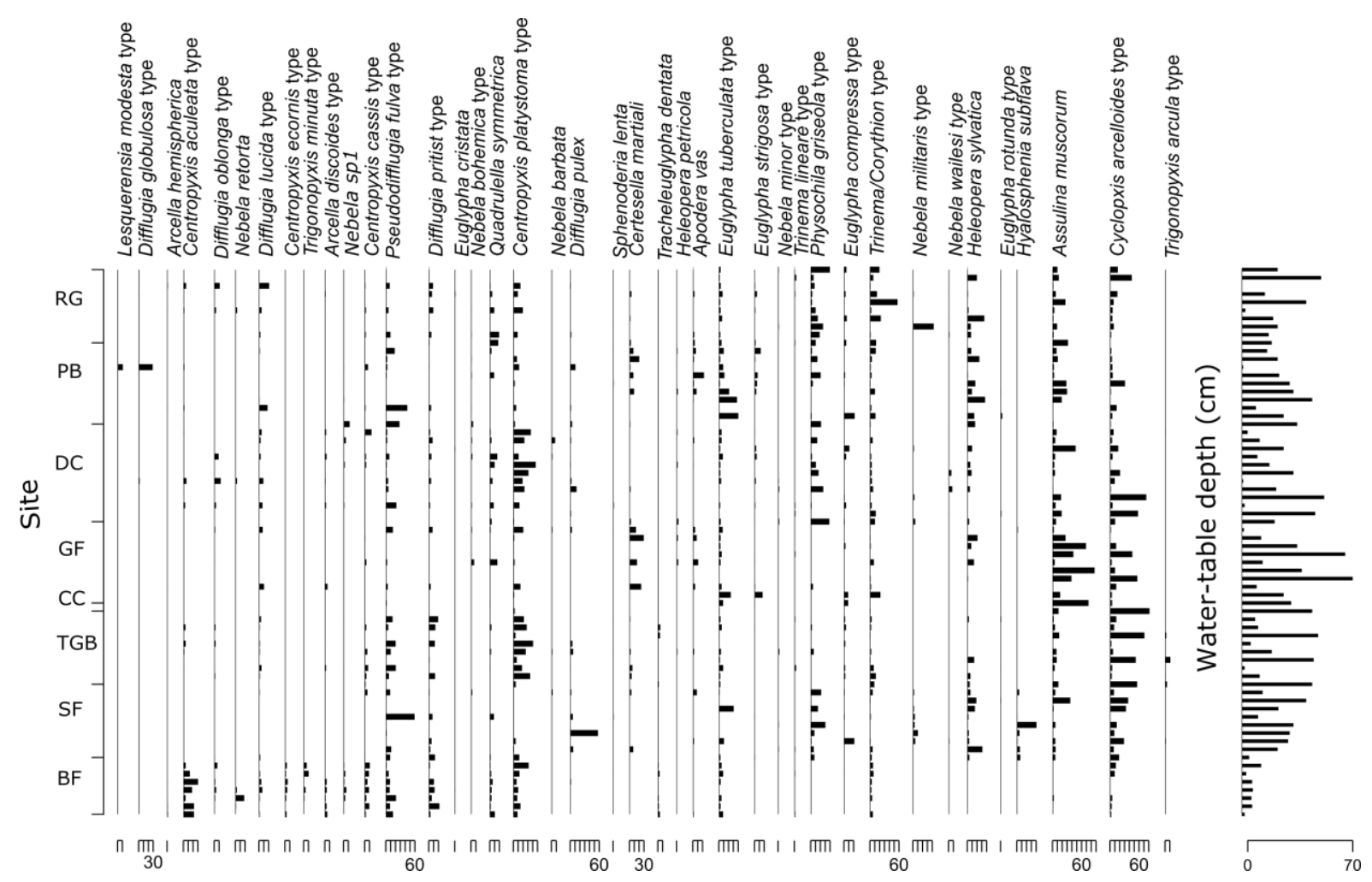


Figure 3: CCA triplot for testate amoebae, samples and environmental variables ('WTD' = watertable depth; $\mathrm{pH}$; 'EC' = electrical conductivity; 'Moisture' = moisture content). Species are scaled proportional to eigenvalues. Names of testate amoebae taxa are shortened but are provided in full in Supplementary Table 2. Samples are identified numerically alongside the first name of the sites (BF = Blundells Flat; $\mathrm{SF}=$ Snowy Flat; TGB = Tom Gregory Bog; $\mathrm{CC}=$ Coronet Creek; GF = Ginini Flat; DC = Digger Creek; PB = Pengillys Bog; RG = Rennix Gap; see also Table 1).

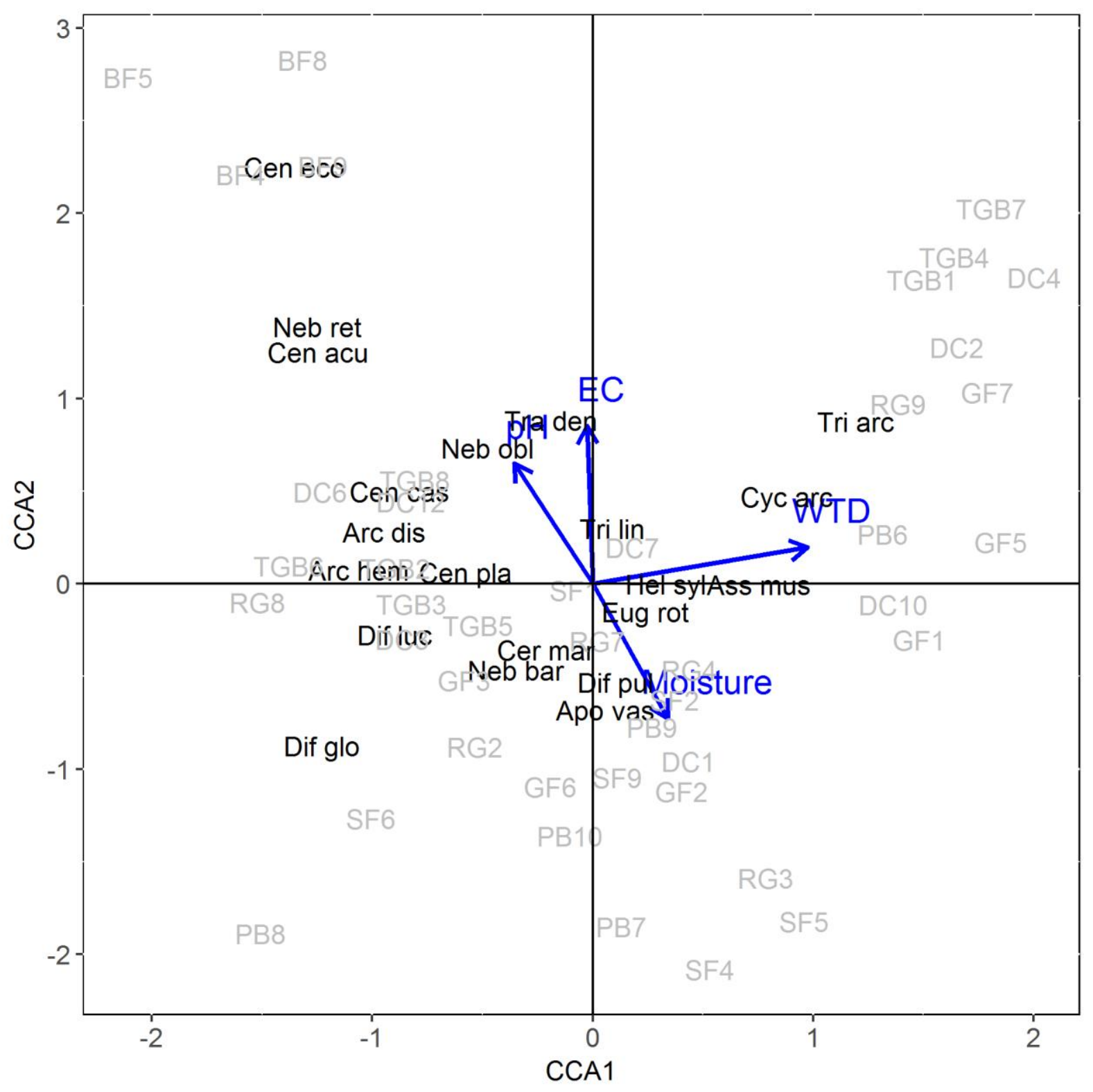


Figure 4: Optima and tolerances, representing the niche centres and breadths for testate amoebae (derived from the weighted average (classical deshrinking WA.cla) transfer function and leave-oneout (LOO) cross validation).

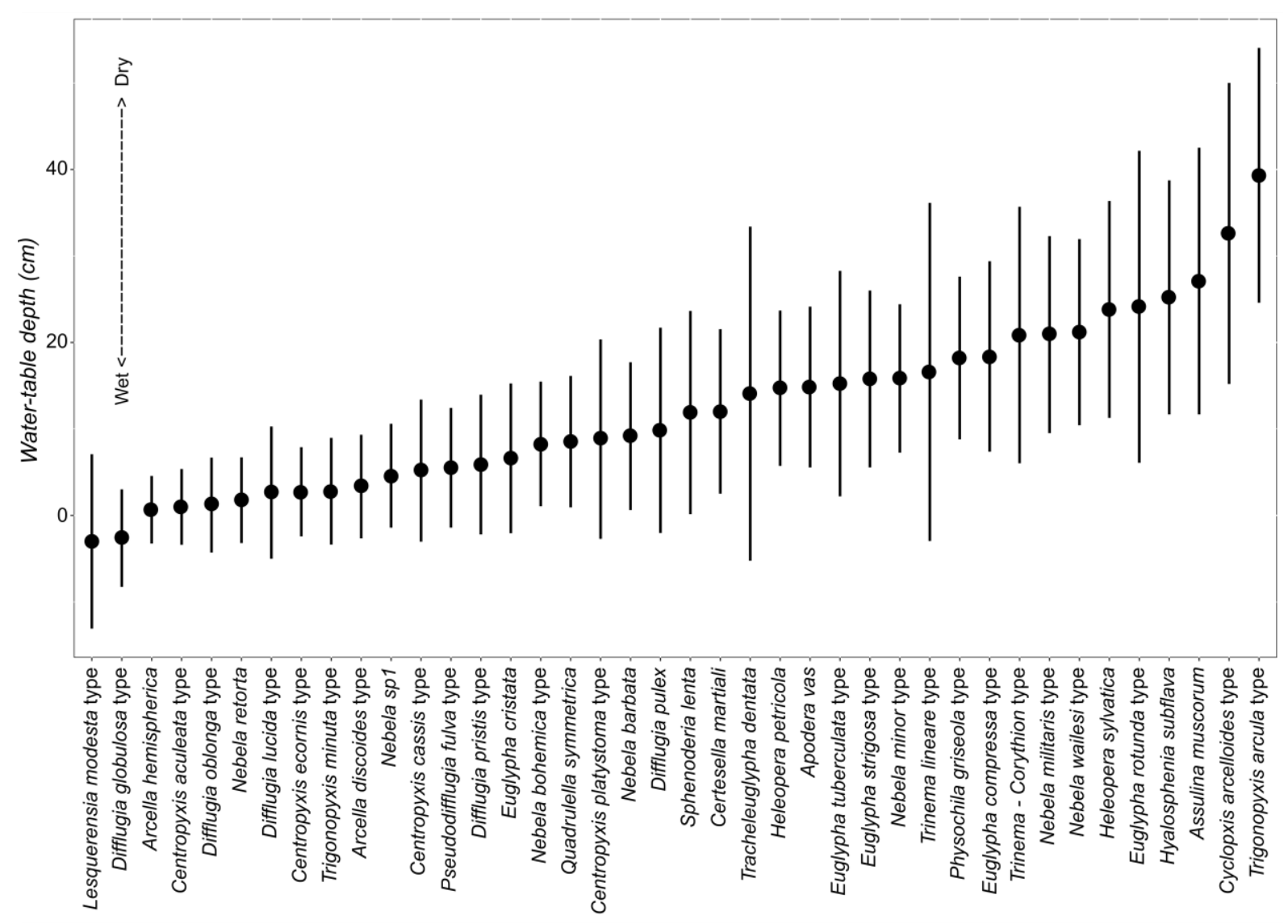


Figure 5: Selection of optimal species-pruned transfer functions for six model types (WA.inv, WA.cla, WA.Tol.inv, WA.Tol.cla, MAT and ML). Plots show the effect on root mean squared error of prediction (RMSEP) of gradually removing taxa, keeping those determined as important to the environmental variable of interest, water-table depth (see text for details). Dashed red lines show the number of taxa remaining in each optimised species pruned model.
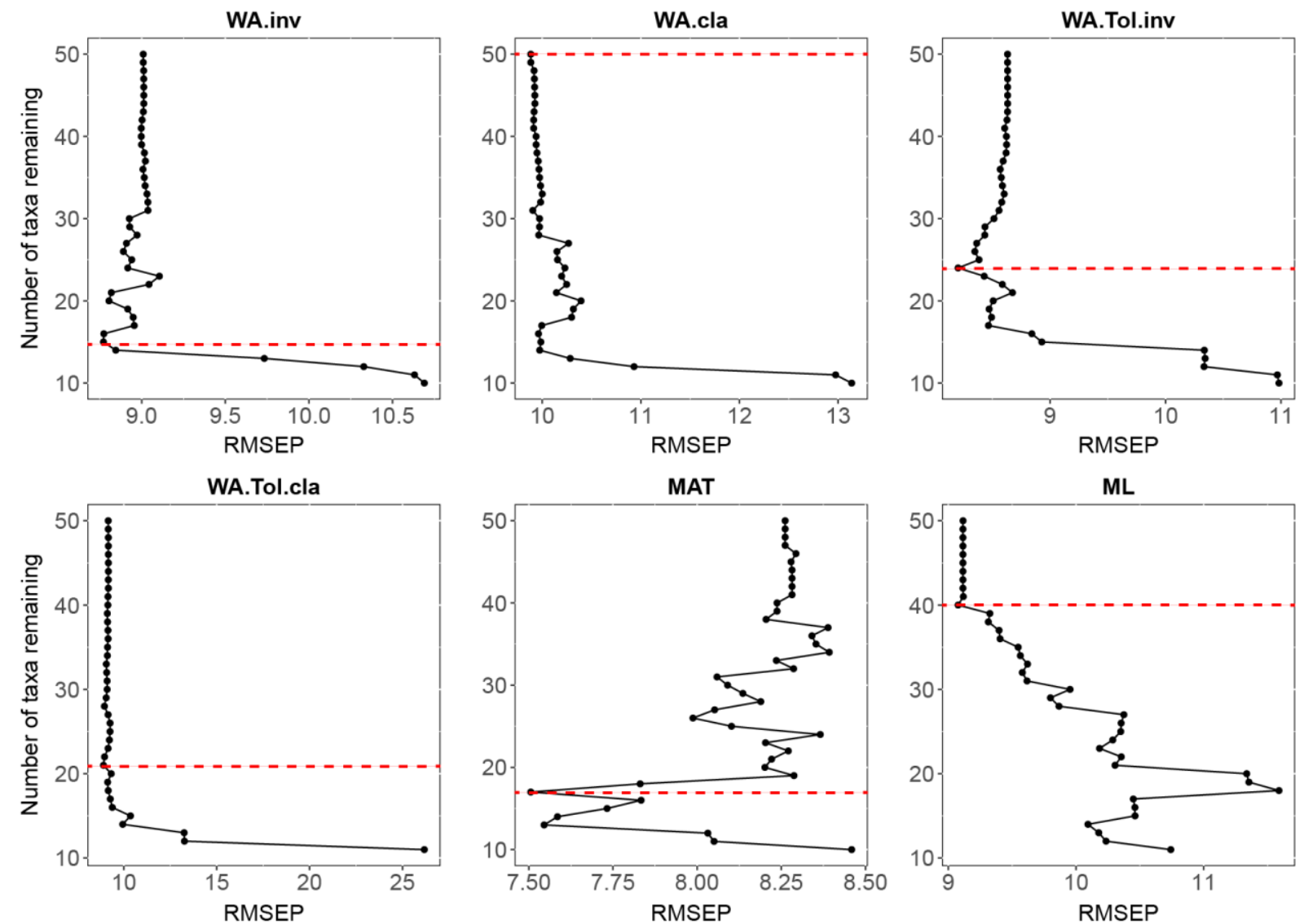
Table 1: Site details for the modern data set.

\begin{tabular}{cccccccc}
\hline Site name & Latitude & Longitude & $\begin{array}{c}\text { Elevation } \\
(\mathrm{m} \text { a.s.I) }\end{array}$ & $\mathrm{pH}$ & $\begin{array}{c}\mathrm{EC} \\
(\mu \mathrm{S} / \mathrm{cm})\end{array}$ & $\begin{array}{c}\text { No. } \\
\text { samples }\end{array}$ \\
\hline Blundells Flat (BF) & -35.32 & 148.83 & 762 & $6.64 \pm 0.53$ & $91.14 \pm 11$ & 9 & Carex gaudichaudiana/Carex curta/Lythrum salicaria fen \\
Snowy Flat (SF) & -35.56 & 148.78 & 1609 & $5.59 \pm 0.33$ & $23.85 \pm 12.73$ & 9 & Empodisma minus/Sphagnum cristatum/ Epacris paludosa shrub bog \\
Tom Gregory Bog (TGB) & -35.65 & 148.83 & 1024 & $5.7 \pm 0.44$ & $54.56 \pm 19.74$ & 9 & Empodisma minus/Epacris paludosa/Sphagnum cristatum shrub bog \\
Coronet Creek (CC) & -35.66 & 148.84 & 1102 & 7.07 & 39.6 & 1 & Epacris paludosa/Empodisma minus/Sphagnum cristatum shrub bog \\
Ginini Flat (GF) & -35.52 & 148.77 & 1590 & $5.54 \pm 0.31$ & $38.15 \pm 21.17$ & 10 & Sphagnum cristatum/Empodisma minus/Richea continentis shrub bog \\
Digger Creek (DC) & -36.38 & 148.48 & 1649 & $5.74 \pm 0.34$ & $48.28 \pm 24.38$ & 12 & Empodisma minus/Sphagnum cristatum/Richea continentis shrub bog \\
Pengillys Bog (PB) & -36.38 & 148.41 & 1673 & $5.36 \pm 0.22$ & $26.8 \pm 15.12$ & 10 & Sphagnum cristatum/Empodisma minus/Richea continentis shrub bog \\
Rennix Gap (RG) & -36.36 & 148.50 & 1582 & $5.6 \pm 0.22$ & $38.93 \pm 19.29$ & 10 & Sphagnum cristatum/Empodisma minus/Richea continentis shrub bog \\
\hline
\end{tabular}


Table 2: The performance of all-species transfer functions by leave-one-out (RMSEP Loo $_{\text {), leave-one-site-out (RMSEP }}$ Loso) and segment-wise (RMSEP $_{\text {sw }}$ ) cross

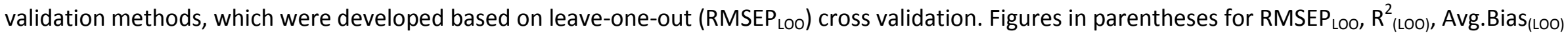
and Max.Bias $(\llcorner O O))$ are the statistical performance after data-screening. Figures in parentheses for RMSEP SW $_{\text {and RMSEP }}$ Loso are the relative decrease or increase compared to corresponding RMSEP $\mathrm{L}_{L O O}$ or RMSEP $\mathrm{P}_{C B}$ after data-screening. SD is the standard deviation of all WTD included in each model after datascreening.

\begin{tabular}{|c|c|c|c|c|c|c|c|c|}
\hline Transfer function & RMSEP LOO $_{2}$ & $R^{2}(L O O)$ & $\operatorname{Avg.Bias}_{(\llcorner O O)}$ & $\operatorname{Max} \operatorname{Bias}_{(\mathrm{LOO})}$ & $\mathrm{RMSEP}_{\mathrm{SW}}$ & RMSEP $_{\text {Loso }}$ & $\begin{array}{c}\text { No. samples } \\
\text { removed }\end{array}$ & SD \\
\hline WA.cla & $9.89(6.22)$ & $0.74(0.85)$ & $0.46(0.37)$ & $17.97(8.75)$ & $6.16(-0.01)$ & $6.99(0.12)$ & 14 & 15.79 \\
\hline WA.Tol.cla & $9.03(6.84)$ & $0.76(0.82)$ & $0.76(0.8)$ & $18.68(7.91)$ & $6.9(0.01)$ & $8.25(0.21)$ & 8 & 15.83 \\
\hline WAPLS(comp1) & $9(6.53)$ & $0.73(0.82)$ & $0.36(0.3)$ & $24.42(10.78)$ & $6.73(0.03)$ & $6.65(0.02)$ & 7 & 15.50 \\
\hline $\operatorname{MAT}(k=4)$ & $8.25(5.73)$ & $0.78(0.86)$ & $0.35(0.56)$ & $17.75(7.38)$ & $5.83(0.02)$ & $5.26(-0.08)$ & 7 & 15.57 \\
\hline
\end{tabular}


Table 3: The performance of species-pruned transfer functions by leave-one-out (RMSEP Loo $_{\text {) }}$, leave-one-site-out (RMSEP LOSO $_{\text {) and segment-wise (RMSEP }}$ ) cross validation methods, which were developed based on leave-one-out (RMSEP ${ }_{\text {LOO }}$ ) cross validation. Figures in parentheses for $R^{2}$ SSEP $_{\text {LOO, }} R^{2}{ }_{(L O O)}$, $\operatorname{Avg}_{\text {Bias }}^{(L O O)}$ and Max.Bias $\left({ }_{(L O)}\right.$ are the statistical performance after data-screening. Figures in parentheses for RMSEP SW $_{\text {and RMSEP }}$ Loso are the relative decrease or increase compared to corresponding RMSEP ${ }_{\text {Loo }}$ data-screening. SD is the standard deviation of all WTD included in each model after datascreening.

\begin{tabular}{|c|c|c|c|c|c|c|c|c|c|}
\hline Transfer function & RMSEP LOO & $\mathrm{R}_{(\mathrm{LOO})}^{2}$ & Avg.Bias(เoO) & $\operatorname{Max} \operatorname{Bias}_{(\mathrm{LOO})}$ & RMSEP $_{S W}$ & RMSEP$_{\text {Loso }}$ & $\begin{array}{l}\text { No. samples } \\
\text { removed }\end{array}$ & SD & $\begin{array}{l}\text { No. taxa } \\
\text { remaining }\end{array}$ \\
\hline WA.cla & $9.88(6.22)$ & $0.74(0.85)$ & $0.44(0.36)$ & $17.99(8.72)$ & $6.17(-0.01)$ & $6.99(0.12)$ & 14 & 15.79 & 50 \\
\hline WA.Tol.cla & $8.91(6.43)$ & $0.78(0.85)$ & $0.67(0.69)$ & 19.05 (5.99) & $6.81(0.06)$ & $6.79(0.06)$ & 8 & 15.94 & 21 \\
\hline $\operatorname{MAT}(k=4)$ & $7.51(5.97)$ & $0.82(0.87)$ & $0.85(0.35)$ & $15.13(18.5)$ & $8.13(0.36)$ & $5.48(-0.08)$ & 7 & 16.64 & 17 \\
\hline$M L$ & $9.08(6.83)$ & $0.77(0.8)$ & $-0.77(-0.34)$ & $15.06(5.41)$ & $7.01(0.03)$ & $7.89(0.16)$ & 7 & 14.92 & 40 \\
\hline
\end{tabular}


Supplementary Figure 1: Images of an undescribed testate amoeba found in this research, herein assigned the name Nebela sp1. The test is approximately $70 \times 40 \mu \mathrm{m}$ in size, oblong in shape and has mosaic plates. The aperture is not perpendiclar to the lateral axis.

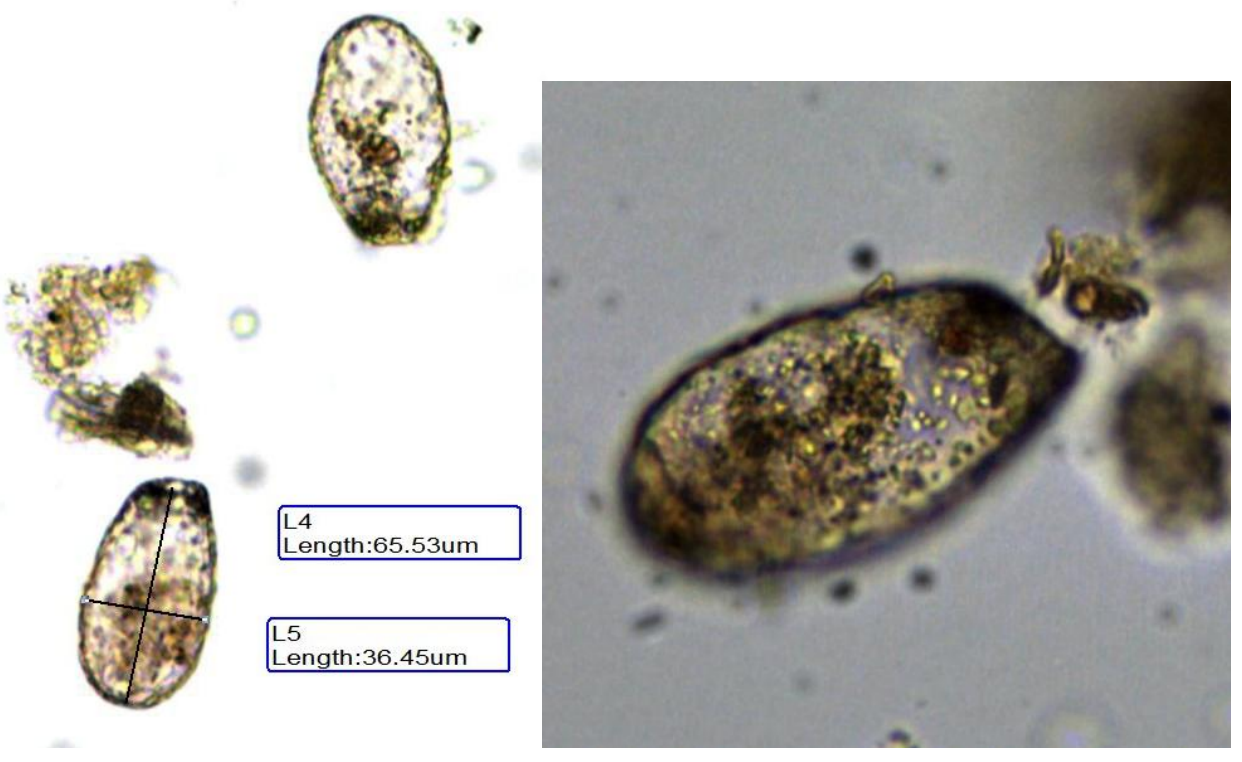


Supplementary Figure 2: Taxa importance index for six different transfer functions. The names of the testate amoebae taxa are shortened versions, with the full names provided in Supplementary Table 2. The $y$-axis is the maximum abundance of the taxa among all samples. The importance index indicates the relative importance of the taxa (with larger numbers indicating greater importance).

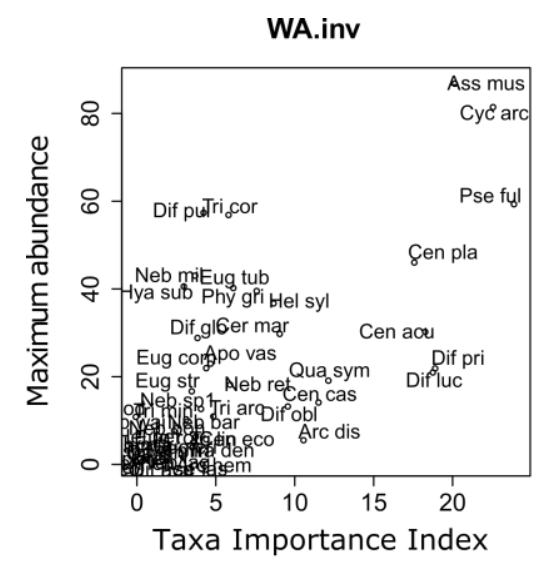

WA.Tol.cla

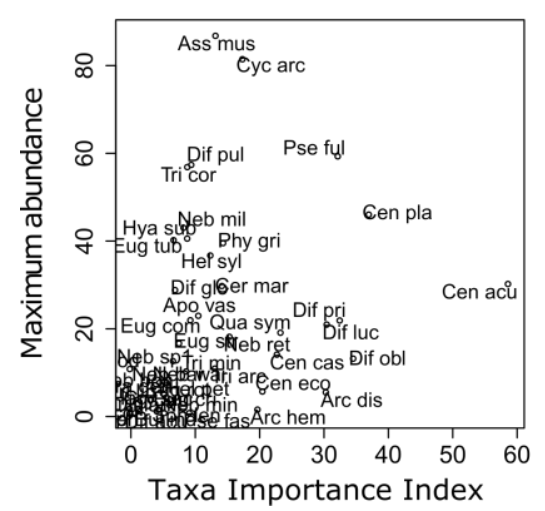

WA.cla

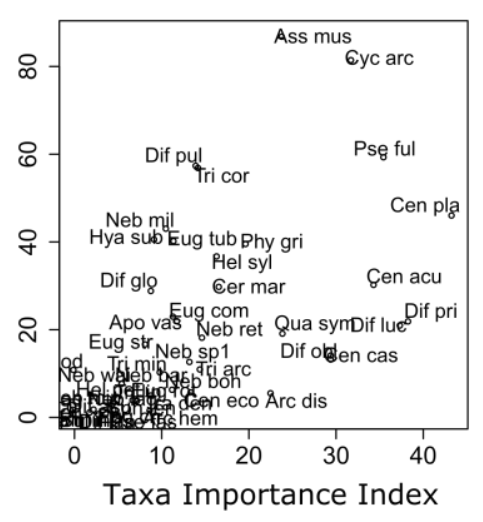

MAT

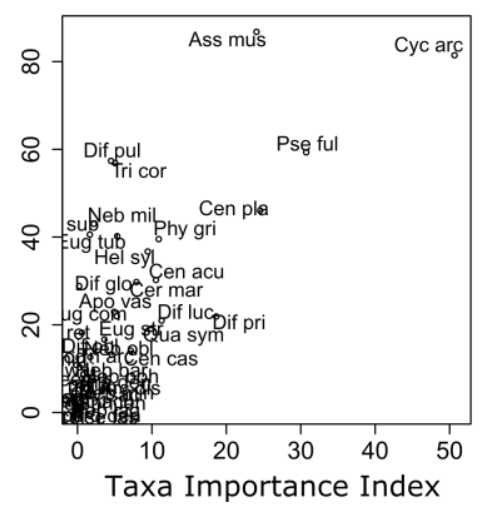

WA.Tol.inv

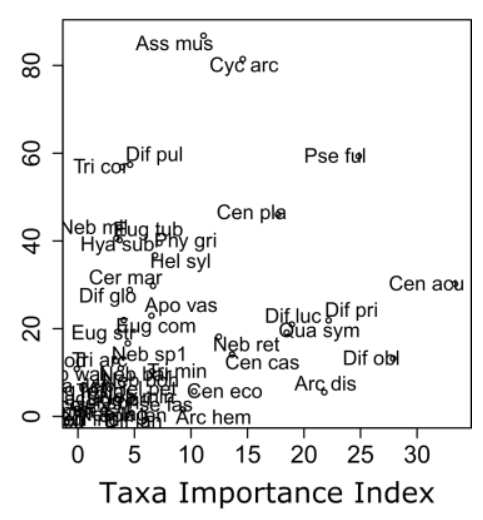

ML

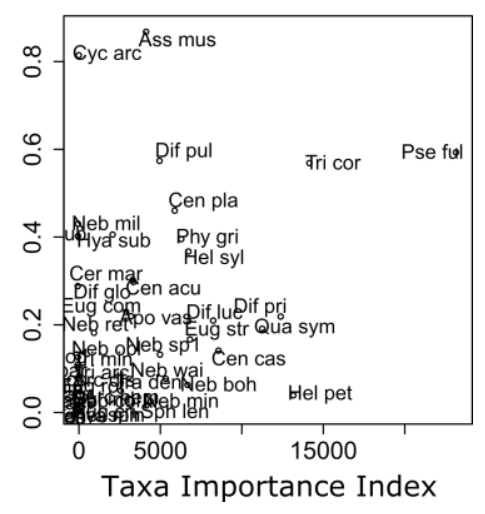


Supplementary Figure 3: Biplots of predicted vs. observed water-table depth (WTD) (A-C and G-I) and residual vs. observed WTD (D-F and J-L) for transfer functions using leave one out (LOO) cross validation before (A-F; e.g. weighted average using classical deshrinking WA.cla_pre) and after (G-L; e.g. WA.cla) data screening for removal of outlier samples. Horizontal dashed lines show the cut-off level (i.e. $20 \%$ of WTD range $=14 \mathrm{~cm}$ ). Green dots represent those samples that were removed as outliers.
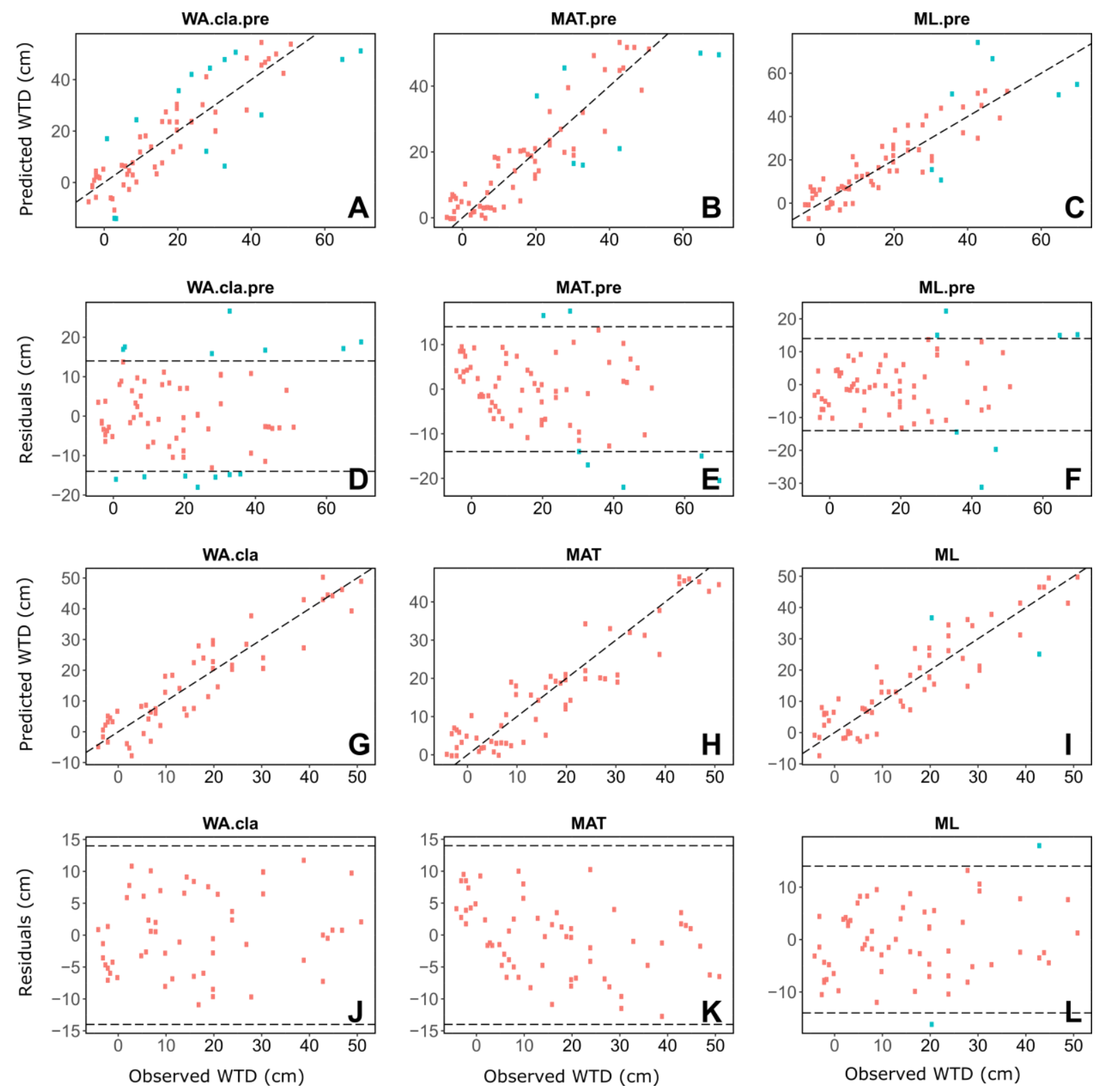
Supplementary Figure 4: Segment-wise root mean squared error of prediction (RMSEP $\left.P_{S w}\right)$ plots for three model types (WA.inv, MAT and ML) based on leave-one-out (LOO) cross validation. Each dataset was divided into 9 equal water table depth segments (see text for details). Grey histograms show the sampling frequency of each segment (left-hand y-axis). Green lines are the individual RMSEP values for each segment (right-hand y-axis). Red dashed lines show the RMSEP Sw $_{\text {(i.e. mean }}$ of all individual segments), compared to RMSEP ${ }_{\text {Loo }}$ (black dashed line). The green line in WA.cla is missing as all samples in this segment were removed during removal of samples with high residual values (see text for details).
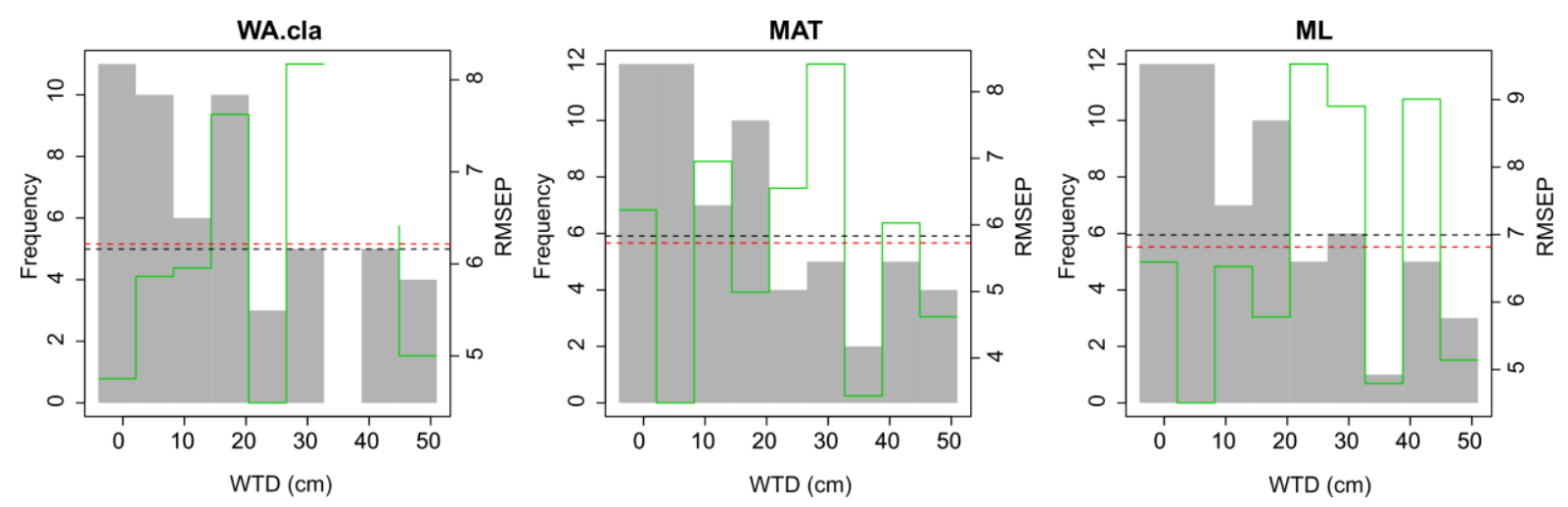
Supplementary Figure 5: Spatial autocorrelation analysis for three model types (WA.cla, MAT, ML) based on leave-one-out (LOO) cross validation. Plots show the effect on model performance (as measured by $\mathrm{R}^{2}$ ) of removing samples by three different methods: 1 ) by random (open circles, black solid line); 2) by geographical proximity (filled circles, dashed black line); and 3) by environmental proximity (red crosses, red dashed line).
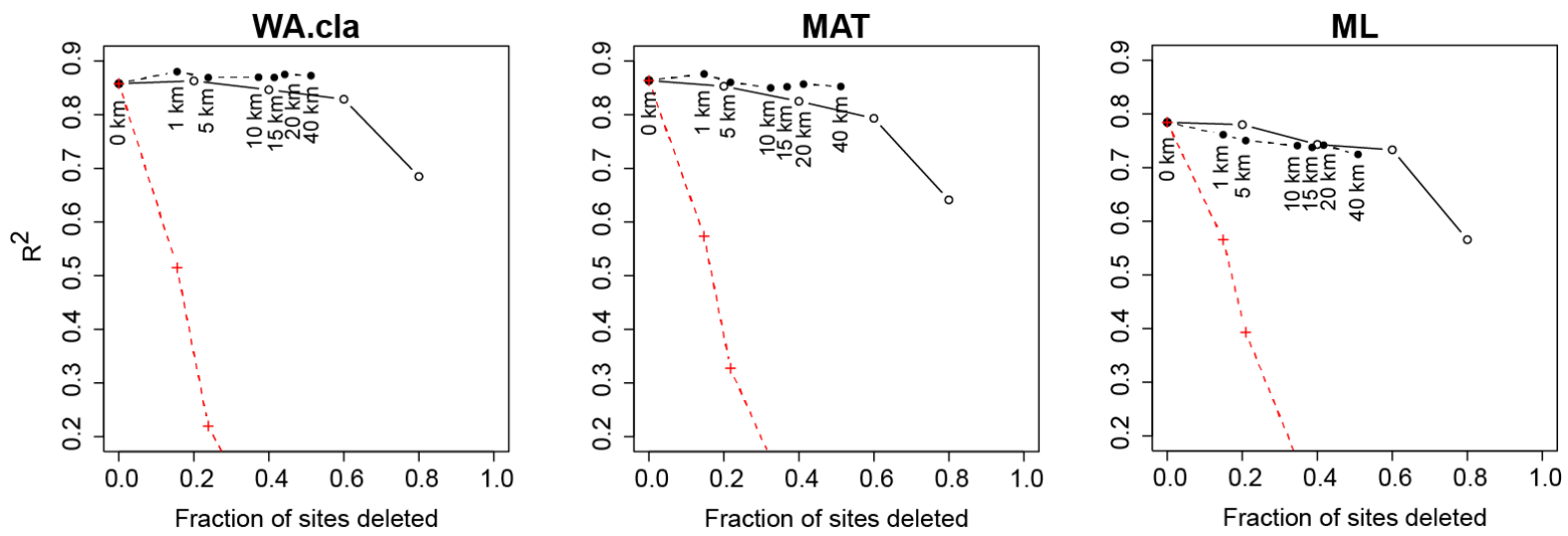
Supplementary Table 1: Laboratory methods used for the preparation of the modern testate amoeba samples.

\begin{tabular}{|l|l|}
\hline Step 1 & $\begin{array}{l}\text { Mix 3-5 g of sediment sample with 1 drop of household detergent } \\
\text { in a beaker with } 200 \mathrm{ml} \text { reverse osmosis water, stir well and leave } \\
\text { overnight }\end{array}$ \\
\hline Step 2 & $\begin{array}{l}\text { Sieve through three-nested sieves }(250 \mu \mathrm{m}, 215 \mu \mathrm{m} \text { and } \\
20 \mu \mathrm{m}), \text { retaining the fraction between } 215 \mu \mathrm{m} \text { and } 20 \mu \mathrm{m}\end{array}$ \\
\hline Step 3 & $\begin{array}{l}\text { Add } 5 \mathrm{ml} 10 \% \mathrm{NaOH}, 25 \mathrm{ml} \text { acetone and } 20 \mathrm{ml} \text { reverse osmosis } \\
\text { water to the samples }\end{array}$ \\
\hline Step 4 & Warm on a hotplate (preheated to $\left.80^{\circ} \mathrm{C}\right)$ for 5 minutes \\
\hline Step 5 & $\begin{array}{l}\text { Sieve through the three-nested sieves, retaining the fraction } \\
\text { between } 215 \mu \mathrm{m} \text { and } 20 \mu \mathrm{m}\end{array}$ \\
\hline Step 6 & Centrifuge for 5 mins at 3,000 rpm \\
\hline Step 7 & $\begin{array}{l}\text { Mount on microscope slides with reverse osmosis water (sealing } \\
\text { a } 22 \times 55 \mathrm{~mm} \text { coverslip with nail polish) }\end{array}$ \\
\hline
\end{tabular}


Supplementary Table 2: A list of all testate amoebae identified across all sites. Site name abbreviations can be found in Figure 1 and Table 1.

\begin{tabular}{|c|c|c|c|c|}
\hline Taxa & Abbreviated name & $\begin{array}{l}\text { Occurrence (number of } \\
\text { samples out of } 68 \text { ) }\end{array}$ & Max abundance (\%) & Sites where the taxa occurred \\
\hline Apodera vas & Apo vas & 30 & 23.14 & $\mathrm{BF}, \mathrm{SF}, \mathrm{TGB}, \mathrm{GF}, \mathrm{DC}, \mathrm{PB}, \mathrm{RG}$ \\
\hline Arcella discoides type & Arc dis & 23 & 5.69 & $\mathrm{BF}, \mathrm{SF}, \mathrm{TGB}, \mathrm{GF}, \mathrm{DC}, \mathrm{RG}$ \\
\hline Arcella hemispherica & Arc hem & 8 & 1.75 & $\mathrm{BF}, \mathrm{GF}, \mathrm{PB}, \mathrm{RG}$ \\
\hline Argynnia dentistoma type & Arg den & 1 & 0.83 & SF \\
\hline Assulina muscorum & Ass mus & 62 & 86.96 & $\mathrm{BF}, \mathrm{SF}, \mathrm{TGB}, \mathrm{CC}, \mathrm{GF}, \mathrm{DC}, \mathrm{PB}, \mathrm{RG}$ \\
\hline Bullinularia indica & Bul ind & 3 & 1.3 & $\mathrm{SF}$ \\
\hline Centropyxis aculeata type & Cen acu & 22 & 30.39 & $\mathrm{BF}, \mathrm{SF}, \mathrm{TGB}, \mathrm{GF}, \mathrm{DC}, \mathrm{PB}, \mathrm{RG}$ \\
\hline Centropyxis cassis type & Cen cas & 32 & 14.29 & $\mathrm{BF}, \mathrm{SF}, \mathrm{TGB}, \mathrm{GF}, \mathrm{DC}, \mathrm{PB}, \mathrm{RG}$ \\
\hline Centropyxis ecornis type & Cen eco & 7 & 5.88 & $\mathrm{BF}$ \\
\hline Centropyxis platystoma type & Cen pla & 51 & 46.2 & $\mathrm{BF}, \mathrm{SF}, \mathrm{TGB}, \mathrm{CC}, \mathrm{GF}, \mathrm{DC}, \mathrm{PB}, \mathrm{RG}$ \\
\hline Certesella martiali & Cer mar & 31 & 29.93 & $\mathrm{SF}, \mathrm{TGB}, \mathrm{GF}, \mathrm{DC}, \mathrm{PB}, \mathrm{RG}$ \\
\hline Cryptodifflugia sacculus & Cry sac & 1 & 1.94 & TGB \\
\hline Cyclopxis arcelloides type & Cyc arc & 65 & 81.62 & $\mathrm{BF}, \mathrm{SF}, \mathrm{TGB}, \mathrm{CC}, \mathrm{GF}, \mathrm{DC}, \mathrm{PB}, \mathrm{RG}$ \\
\hline Difflugia acuminata & Dif acu & 1 & 0.81 & RG \\
\hline Difflugia globulosa type & Dif glo & 3 & 29 & $\mathrm{DC}, \mathrm{PB}, \mathrm{RG}$ \\
\hline Difflugia lanceolata & Dif lan & 3 & 0.98 & $\mathrm{BF}, \mathrm{TGB}$ \\
\hline Difflugia lucida type & Dif luc & 34 & 21.14 & $\mathrm{BF}, \mathrm{SF}, \mathrm{TGB}, \mathrm{GF}, \mathrm{DC}, \mathrm{PB}, \mathrm{RG}$ \\
\hline Difflugia oblonga type & Dif obl & 18 & 13.38 & $\mathrm{BF}, \mathrm{SF}, \mathrm{TGB}, \mathrm{GF}, \mathrm{DC}, \mathrm{RG}$ \\
\hline Difflugia pritist type & Dif pri & 39 & 22.06 & $\mathrm{BF}, \mathrm{SF}, \mathrm{TGB}, \mathrm{GF}, \mathrm{DC}, \mathrm{PB}, \mathrm{RG}$ \\
\hline Difflugia pulex & Dif pul & 24 & 57.54 & $\mathrm{BF}, \mathrm{SF}, \mathrm{TGB}, \mathrm{GF}, \mathrm{DC}, \mathrm{PB}, \mathrm{RG}$ \\
\hline Euglypha compressa type & Eug com & 30 & 22.12 & $\mathrm{BF}, \mathrm{SF}, \mathrm{TGB}, \mathrm{GF}, \mathrm{DC}, \mathrm{PB}, \mathrm{RG}$ \\
\hline Euglypha cristata & Eug cri & 6 & 1.71 & $B F, S F, D C, R G$ \\
\hline Euglypha rotunda type & Eug rot & 11 & 3.85 & $\mathrm{SF}, \mathrm{TGB}, \mathrm{GF}, \mathrm{DC}, \mathrm{PB}, \mathrm{RG}$ \\
\hline Euglypha strigosa type & Eug str & 24 & 16.83 & $\mathrm{SF}, \mathrm{TGB}, \mathrm{GF}, \mathrm{DC}, \mathrm{PB}, \mathrm{RG}$ \\
\hline Euglypha tuberculata type & Eug tub & 65 & 40.38 & $\mathrm{BF}, \mathrm{SF}, \mathrm{TGB}, \mathrm{CC}, \mathrm{GF}, \mathrm{DC}, \mathrm{PB}, \mathrm{RG}$ \\
\hline Heleopera petricola & Hel pet & 13 & 4.1 & TGB, GF, DC, PB, RG \\
\hline Heleopera sphagni & Hel sph & 1 & 0.98 & GF \\
\hline
\end{tabular}




\begin{tabular}{|c|c|c|c|c|}
\hline Heleopera sylvatica & Hel syl & 48 & 36.88 & SF, TGB, GF, DC, PB, RG \\
\hline Hyalosphenia minuta type & Hya min & 2 & 0.93 & SF, RG \\
\hline Hyalosphenia subflava & Hya sub & 12 & 40.74 & SF, GF, DC, RG \\
\hline Lesquerensia modesta type & Les mod & 1 & 11 & PB \\
\hline Nebela barbata & Neb bar & 9 & 7.86 & SF, TGB, GF, DC, PB, RG \\
\hline Nebela bohemica type & Neb boh & 16 & 6.48 & $\mathrm{SF}, \mathrm{GF}, \mathrm{DC}, \mathrm{PB}, \mathrm{RG}$ \\
\hline Nebela collaris type & Neb col & 1 & 0.94 & TGB \\
\hline Nebela lageniformis & Neb lag & 2 & 1.98 & GF, DC \\
\hline Nebela militaris type & Neb mil & 18 & 43.2 & SF, DC, RG \\
\hline Nebela minor type & Neb min & 13 & 2.75 & $\mathrm{BF}, \mathrm{SF}, \mathrm{TGB}, \mathrm{DC}, \mathrm{RG}$ \\
\hline Nebela sp1 & Neb sp1 & 16 & 12.82 & $\mathrm{BF}, \mathrm{SF}, \mathrm{TGB}, \mathrm{DC}, \mathrm{PB}, \mathrm{RG}$ \\
\hline Nebela retorta & Neb ret & 9 & 18.35 & $\mathrm{BF}, \mathrm{TGB}, \mathrm{DC}, \mathrm{RG}$ \\
\hline Nebela wailesi type & Neb wai & 13 & 7.88 & SF, DC, RG \\
\hline Physochila griseola type & Phy gri & 42 & 39.71 & SF, TGB, GF, DC, PB, RG \\
\hline Pseudodifflugia fasciularis & Pse fas & 4 & 0.95 & $\mathrm{DC}, \mathrm{RG}$ \\
\hline Pseudodifflugia fulva type & Pse ful & 46 & 59.49 & $\mathrm{BF}, \mathrm{SF}, \mathrm{TGB}, \mathrm{GF}, \mathrm{DC}, \mathrm{PB}, \mathrm{RG}$ \\
\hline Quadrulella symmetrica & Qua sym & 33 & 19.28 & $\mathrm{BF}, \mathrm{SF}, \mathrm{TGB}, \mathrm{GF}, \mathrm{DC}, \mathrm{PB}, \mathrm{RG}$ \\
\hline Sphenoderia lenta & Sph len & 13 & 1.82 & $\mathrm{BF}, \mathrm{SF}, \mathrm{TGB}, \mathrm{GF}, \mathrm{DC}, \mathrm{PB}, \mathrm{RG}$ \\
\hline Tracheleuglypha dentata & Tra den & 14 & 5.17 & $\mathrm{BF}, \mathrm{TGB}, \mathrm{GF}, \mathrm{RG}$ \\
\hline Trigonopyxis arcula type & Tri arc & 6 & 11.11 & SF, TGB, DC \\
\hline Trinema/Corythion type & Tri cor & 60 & 57.04 & $\mathrm{BF}, \mathrm{SF}, \mathrm{TGB}, \mathrm{CC}, \mathrm{GF}, \mathrm{DC}, \mathrm{PB}, \mathrm{RG}$ \\
\hline Trinema lineare type & Tri lin & 22 & 4 & $\mathrm{BF}, \mathrm{SF}, \mathrm{TGB}, \mathrm{GF}, \mathrm{DC}, \mathrm{RG}$ \\
\hline Trigonopyxis minuta type & Tri min & 4 & 10.45 & $\mathrm{BF}$ \\
\hline
\end{tabular}


Supplementary Table 3: a) Results from CCA on constrained proportion. b) Results from CCA for separate constrained axis (*** $=p<0.001)$.

Table 3a.

\begin{tabular}{|l|c|c|}
\hline & Inertia & Proportion \\
\hline Total & 3.75 & 1.00 \\
\hline Constrained & 0.68 & 0.18 \\
\hline Unconstrained & 3.06 & 0.82 \\
\hline
\end{tabular}

Table 3b.

\begin{tabular}{|l|c|c|}
\hline & ${\text { CCA axis } 1^{* * *}}^{\text {CCA axis 2 }}$ \\
\hline Eigenvalue & 0.40 & 0.20 \\
\hline Proportion Explained & 0.59 & 0.29 \\
\hline Cumulative Proportion & 0.59 & 0.87 \\
\hline
\end{tabular}


Supplementary Table 4: The performance of all-species transfer functions performance by cluster-bootstrap RMSEP $\mathrm{CB}_{\mathrm{CB}}$, leave-one-site-out (RMSEP $\mathrm{LOso}_{\mathrm{O} O}$ ) and segment-wise $\left(R M S E P_{S w}\right)$ cross validation methods, which were developed based on RMSEP $P_{C B}$. Figures in parentheses for $R_{M S E P} P_{C B}, R_{(C B)}^{2}, A_{v g} \cdot B_{i a s}(C B)$ and Max.Bias $_{(\mathrm{CB})}$ are the statistical performance after data-screening. Figures in parentheses for RMSEP $\mathrm{SW}_{S W}$ and RMSEP Loso are the relative decrease or increase compared to corresponding RMSEP ${ }_{L O O}$ or RMSEP ${ }_{C B}$ after data-screening. SD is the standard deviation of all WTD included in each model after data-screening.

\begin{tabular}{|c|c|c|c|c|c|c|c|c|}
\hline $\begin{array}{l}\text { Transfer } \\
\text { function }\end{array}$ & $\mathrm{RMSEP}_{\mathrm{CB}}$ & $\mathrm{R}_{(\mathrm{CB})}^{2}$ & Avg.Bias $_{(\mathrm{CB})}$ & $\operatorname{Max} \operatorname{Bias}_{(\mathrm{CB})}$ & $\mathrm{RMSEP}_{\mathrm{SW}}$ & RMSEP $_{\text {Loso }}$ & $\begin{array}{l}\text { No. samples } \\
\text { removed }\end{array}$ & SD \\
\hline WA.inv & 9.72 (7.19) & $0.7(0.81)$ & $-1.66(-0.94)$ & 14.71 (15.89) & $7.53(0.05)$ & $6.51(-0.09)$ & 7 & 15.54 \\
\hline WA.Tol.inv & $9.62(7.61)$ & $0.73(0.8)$ & $-2.42(-1.85)$ & 12.74 (12.79) & $7.87(0.03)$ & $6.65(-0.13)$ & 5 & 15.45 \\
\hline WA.Tol.cla & $10.2(7.56)$ & $0.73(0.8)$ & $-3.14(-1.97)$ & $15.45(12.97)$ & $7.7(0.02)$ & $6.46(-0.15)$ & 9 & 15.59 \\
\hline $\operatorname{MAT}(\mathrm{k}=4)$ & $8.24(5.75)$ & $0.8(0.86)$ & $-0.49(-0.27)$ & $32.75(23.75)$ & $5.86(0.02)$ & $5.3(-0.08)$ & 6 & 15.45 \\
\hline
\end{tabular}

